\title{
Facile microwave synthesis and photocatalytic activity of monodispersed $\mathrm{BaTiO}_{3}$ nanocuboids
}

\author{
Pei Chen, ${ }^{* 1}$ Yantao Zhang, ${ }^{1}$ Fengqi Zhao, ${ }^{2}$ Hongxu Gao, ${ }^{2}$ Xinbing Chen, ${ }^{1}$ and Zhongwei An ${ }^{1,2}$ \\ ${ }^{1}$ Key Laboratory of Applied Surface and Colloid Chemistry (MOE), School of Materials Science and \\ Engineering, Shaanxi Normal University, Xi'an 710062, PR China \\ ${ }^{2}$ Science and Technology on Combustion and Explosion Laboratory, Xi'an Modern Chemistry Research \\ Institute, Xi'an 710065, PR China \\ Corresponding E-mail: chenpei@snnu.edu.cn
}

\begin{abstract}
A facile microwave hydrothermal method for preparation of monodispersed barium titanate $\left(\mathrm{BaTiO}_{3}\right)$ nanocuboids with average size of $13 \mathrm{~nm}$ is developed, and the effects of synthesis parameters, such as molar composition of the precursor, synthesis time and temperature, on the morphology of $\mathrm{BaTiO}_{3}$ nanocrystals are systematically evaluated. The resulting products are characterized by X-ray diffraction (XRD), Raman spectrum, infrared spectrum (IR), UV-vis diffuse reflectance spectrum, water contact angle, thermogravimetry (TG), scanning electron microscopy (SEM), high-resolution transmission electron microscopy (HR-TEM), and selected area electron diffraction (SAED). A possible formation mechanism of $\mathrm{BaTiO}_{3}$ nanocuboids is proposed. The $\mathrm{BaTiO}_{3}$ nanocuboids show high photocatalytic activity for the degradation of Rhodamin B under UV irradiation.
\end{abstract}

Keywords monodispersed, $\mathrm{BaTiO}_{3}$, nanocuboids, preparation, photocatalysis

\section{Introduction}

Barium titanate $\left(\mathrm{BaTiO}_{3}\right)$ is well-known electroceramic material and widely used in the electronic industry [1]. Recently, monodispersed $\mathrm{BaTiO}_{3}$ nanocrystals have attracted more and more attentions than $\mathrm{BaTiO}_{3}$ bulk materials [2], due to their excellent properties, such as high bioimaging [3] improved 
dielectric properties, potential for device miniaturization, photocatalytic activity, and so on. Furthermore, Because the band gap of $\mathrm{BaTiO}_{3}$ nanocrystal is close to that of $\mathrm{TiO}_{2}[4]$ indicates its potentiality in the field of photocatalysis. which make it pessible to act as an effective photocatalyst. It has been reported that $\mathrm{BaTiO}_{3}$ can degrade organic dyes like methyl red [5], crystal violet [6] and methyl orange [7] under super-band-gap irradiation. Further research shows that the tetragonal phase of $\mathrm{BaTiO}_{3}$ exhibit better photocatalytic performance than the cubic phase [8], which is contributed to the influence of the ferroelectricity on the carrier separation and stern layer formation. All these results indicate that $\mathrm{BaTiO}_{3}$ is a very interesting material for photocatalysis. However, $\mathrm{BaTiO}_{3}$ nanocrystals obtained in these works have large size $(>55 \mathrm{~nm})$ and irregular shape. It is well known that $\mathrm{BaTiO}_{3}$ nanocrystals with small size and special crystal planes show high photocatalytic activity due to their enough active sites. Thus, it is very important to prepare $\mathrm{BaTiO}_{3}$ nanocrystals with small size and uniform shape.

Until to now, much effort has been given to $\mathrm{BaTiO}_{3}$ morphology-controlled synthesis including size and shape [9-10], and various shapes, such as nanorods [11], nanotubes [12], nanowires [13], and nanocubes [14], have been successfully prepared. Among them, cube or cuboid nanocrystals have seemly more advantages in acting as building blocks for $\mathrm{BaTiO}_{3}$ thin film which is desirable for advanced device applications [15], and thus have attracted some attentions.

Some valuable trials have been done on synthesis of cube or cuboid shaped $\mathrm{BaTiO}_{3}$ nanocrystals. For example, Hou et al. prepared $\mathrm{BaTiO}_{3}$ nanocubes by solvothermal method [16]. Yan et al. [17] used the $\mathrm{BaTiO}_{3}$ seeds second growth method under hydrothermal condition to prepare $\mathrm{BaTiO}_{3}$ nanocubes. Liu et al prepared cube or cuboid shaped $\mathrm{BaTiO}_{3}$ nanocrystals in a solution of composite-hydroxide eutectic [18]. But $\mathrm{BaTiO}_{3}$ nanocrystals obtained by these methods have slight large size $(30-90 \mathrm{~nm})$ and present cube shape with round-corner. Then smaller size and sharp-edge cube shaped $\mathrm{BaTiO}_{3}$ nanocrystals are prepared. Adireddy et al successfully prepared regular $\mathrm{BaTiO}_{3}$ nanocubes with size of about $22 \mathrm{~nm}$ by hydrothermal 
method under an inert atmosphere using butanol/ $\mathrm{H}_{2} \mathrm{O}$ as solvent at $135{ }^{\circ} \mathrm{C}$ for $18 \mathrm{~h}$ [19]. Wada et al prepared $\mathrm{BaTiO}_{3}$ nanocubes with $12-15 \mathrm{~nm}$ via solvothermal method at $240{ }^{\circ} \mathrm{C}$ for $18 \mathrm{~h}$, where 2-methoxyethanol/ethanol (40: 60, vol. \%) was used as solvent [20]. Zhou et al prepared monodispersed sub-10 $\mathrm{nm} \mathrm{BaTiO}{ }_{3}$ nanocubes by using ethanol as solvent and $\mathrm{OA}$ as the surfactant at $160{ }^{\circ} \mathrm{C}$ for $12 \mathrm{~h} \mathrm{[21]}$. In these literatures, the organic solvent and longer synthetic time than $10 \mathrm{~h}$ are necessary to obtain sub-20 $\mathrm{nm} \mathrm{BaTiO}_{3}$ nanocubes. However, organic solvents are costly and unfavorable for environment, and long heating time results in much higher energy consumption.

Hydrothermal microwave method is commonly used to prepare inorganic materials due to its short synthesis time and convenient process, and is a good alternative for conventional hydrothermal synthesis. Until to now, there have few reports on the preparation of $\mathrm{BaTiO}_{3}$ nanocrystals via hydrothermal microwave method. Recently, Moreira et al have prepared $\mathrm{BaTiO}_{3}$ nanocrystals at $140{ }^{\circ} \mathrm{C}$ for 10 min using hydrothermal microwave method, but the obtained nanocrystals show spherical shape and large size nearly $100 \mathrm{~nm}$ [22]. In this study, we present a microwave hydrothermal method to prepare monodispersed $\mathrm{BaTiO}_{3}$ nanocuboids with average size about $13 \mathrm{~nm}$, which can be achieved at $200{ }^{\circ} \mathrm{C}$ for $4 \mathrm{~h}$ just using water as solvent. Further, the effects of crystallization temperature, time and the molar composition of the precursor mixture on the morphology of $\mathrm{BaTiO}_{3}$ nanocrystals are systematically investigated, and then the formation mechanism and photocatalytic activity of the resultant $\mathrm{BaTiO}_{3}$ nanocubids are studied.

\section{Material and methods}

Barium hydroxide octahydrate $\left(\mathrm{Ba}(\mathrm{OH})_{2} \cdot 8 \mathrm{H}_{2} \mathrm{O}\right.$, purity $\left.98 \%\right)$, barium nitrate $\left(\mathrm{Ba}\left(\mathrm{NO}_{3}\right)_{2}\right.$, purity $\left.98 \%\right)$, barium chloride $\left(\mathrm{BaCl}_{2}\right.$, purity $\left.98 \%\right)$, sodium hydroxide $(\mathrm{NaOH}$, purity $98 \%)$, titanium (IV) n-butoxide (TBOT, purity 98\%), oleic acid (OA, purity 99\%) and Rhodamin B (RhB) were purchased from Sinophram Chemical Regent Co. Ltd (Shanghai, China) and used without any further purification.

\subsection{Synthesis of $\mathrm{BaTiO}_{3}$ nanocuboids}


In a typical procedure for the preparation of $\mathrm{BaTiO}_{3}$ nanocuboids, $0.45 \mathrm{~g}$ of $\mathrm{Ba}(\mathrm{OH})_{2} \cdot 8 \mathrm{H}_{2} \mathrm{O}$ was dissolved in $10 \mathrm{~mL}$ of deionized water, to which $0.125 \mathrm{~mL}$ of $\mathrm{OA}$ was added, and white precipitate of barium oleate immediately occurred. The mixture was stirred for $30 \mathrm{~min}$. And then $0.40 \mathrm{~g}$ of TBOT was poured into the mixture. After stirred for another $30 \mathrm{~min}$, the amount of white precipitate increased due to the formation of amorphous titania. The resulting mixture subsequently was transferred to a $60 \mathrm{~mL}$ autoclave. The autoclave was then sealed and irradiated at $200{ }^{\circ} \mathrm{C}$ for $4 \mathrm{~h}$ under autogenous pressure in a microwave oven (MDS-6, Shanghai Sineo Microwave Chemistry Technology Co. Ltd, China) (with a rotator), which was operated at $2.45 \mathrm{GHz}$ and with output power of up to $1000 \mathrm{~W}$. After the reaction mixture was cooled naturally to room temperature, the solid product was separated from the supernatant solution by centrifugation. No size selection was performed to narrow the size distribution of the nanoparticles. The precipitate was washed with water and ethanol, and then dried at $60{ }^{\circ} \mathrm{C}$ for $12 \mathrm{~h}$ in vacuum oven. In order to investigate the effect of synthesis parameters, the following synthesis parameters were evaluated: crystallization temperature/time, molar ratios of $\mathrm{H}_{2} \mathrm{O} / \mathrm{Ba}, \mathrm{OA} / \mathrm{Ba}$ and $\mathrm{Ba} / \mathrm{Ti}$ (Table 1).

\subsection{Characterization of $\mathrm{BaTiO}_{3}$ nanocuboids}

The crystal structure and purity of the dried products were studied by powder X-Ray diffraction (XRD) (Rigalcu, D/Max-3c, $\mathrm{Cu} \mathrm{K} \alpha$ radiation) and Raman microscope spectrometer (Renishaw inVia Reflex, excitation at $532 \mathrm{~nm}$ ) at room temperature. The shape, crystal structure and particle size were analysized by transmission electron microscopy (TEM, JEOL 2100) equipped with selected area electron diffraction (SAD). The presence of OA molecules on the surface of $\mathrm{BaTiO}_{3}$ nanocrystals was characterized with a Fourier transform infrared spectrometer (FT-IR, Brucher, Tensor27), Thermogravimetry (TG) analyses (TA Q50, heating rate of $10{ }^{\circ} \mathrm{C} \mathrm{min}^{-1}$, nitrogen flow of $40 \mathrm{~mL} \cdot \mathrm{min}^{-1}$ ) and contact angle analyzer (OCA 20, Dataphysics). UV-vis diffuse reflectance spectrum was recorded on a UV spectrophotometer (Shimadzu, UV-3600) at room temperature. 


\subsection{Photocatalytic experiments}

The photocatalytic activity of the $\mathrm{BaTiO}_{3}$ nanocuboids was examined via a model reaction of $\mathrm{RhB}$ degradation under UV irradiation. The typical experiment was carried out as follows. A certain amount of the $\mathrm{BaTiO}_{3}$ powder was added to $30 \mathrm{~mL}$ of $\mathrm{RhB}$ solution with a certain concentration. In order to investigate the influence of catalyst amount and the concentration of $\mathrm{RhB}, 10,20,40$ and $60 \mathrm{mg}$ of $\mathrm{BaTiO}_{3}$ powder were added into $30 \mathrm{~mL}$ of $10 \mathrm{mg} / \mathrm{L} \mathrm{RhB}$ solution, respectively; and $10 \mathrm{mg}$ of $\mathrm{BaTiO}_{3}$ powder were added into $30 \mathrm{~mL}$ of 5,10,15 and $20 \mathrm{mg} / \mathrm{L} \mathrm{RhB}$ solution, respectively. Prior to irradiation, the suspensions were magnetically stirred for $30 \mathrm{~min}$ in the dark to establish the adsorption/desorption equilibrium between dye and $\mathrm{BaTiO}_{3}$ nanocrystals. Then, the mixed solution was transferred into a $50 \mathrm{~mL}$ quartz test tube and irradiated with a $300 \mathrm{~W} \mathrm{Hg}$ lamp $(365 \mathrm{~nm})$ at a distance of about $10 \mathrm{~cm}$ (XPA-7 photochemical reactor, Xujiang Electromechanical Plant, Nanjing, China). At a given irradiation time interval, the samples were drawn from the test tube and were immediately centrifuged at $10000 \mathrm{r} / \mathrm{min}$ to remove catalyst particles for analysis. The absorption spectra of these solutions were measured by a TU-1901 Ultraviolet-Visible spectrophotometer (Beijing Purkinje General Instrument Co. Ltd., Beijing, China). The degradation efficiency can be calculated as: efficiency $(\%)=100 \% *\left(\mathrm{C}_{\mathrm{o}}-\mathrm{C}\right) / \mathrm{C}_{\mathrm{o}}$, where $\mathrm{C}_{\mathrm{o}}$ is the initial concentration of $\mathrm{RhB}$, and $\mathrm{C}$ is the revised concentration considering $\mathrm{RhB}$ adsorption on $\mathrm{BaTiO}_{3}$ after photoirradiation. The concentration of $\mathrm{RhB}$ is calculated by a calibration curve. The maximum absorption of $\mathrm{RhB}$ is at wavelengths of $554 \mathrm{~nm}$.

\section{Results and discussions}

\subsection{Characterization of $\mathrm{BaTiO}_{3}$ nanocuboids}

The products, which are prepared BaTiO3 nanocuboids are successfully prepared after microwave heating the precursor solution with a molar composition of $\mathrm{Ba}(\mathrm{OH})_{2}: 0.83 \mathrm{Ti}(\mathrm{OBu})_{4}: 0.3 \mathrm{OA}: 394 \mathrm{H}_{2} \mathrm{O}$ at $200{ }^{\circ} \mathrm{C}$ for $4 \mathrm{~h}$, are characterized by and XRD pattern, Raman spectrum spectrometer and TEM image are 
shown in Fig.1. From XRD pattern (Fig. 1a); it is found that the product is single perovskite structure. In addition, a very weak peak at $2 \theta=23.9^{\circ}$ assigned to barium carbonate is also observed, which might originate from the carbonate impurities contained in the raw materials and can be easily removed by washing with $0.1 \mathrm{~mol} / \mathrm{L}$ formic acid solution. The average crystal size calculated from the Debye-Scherrer equation by taking account of the peak broadening at [111] diffraction is about $20 \mathrm{~nm}$. In addition, the diffraction pattern in the $2 \theta$ region of $40-50^{\circ}$ is usually characteristic of the presence of either cubic or tetragonal $\mathrm{BaTiO}_{3}$ structure. In this case, no splitting of cubic (200) into tetragonal (200) and (002) reflections at about $45^{\circ}$ can be observed due to line broadening resulted from the size effect [19]. Therefore, it is difficult to assign the crystal symmetry of $\mathrm{BaTiO}_{3}$ nanocrystals to either cubic or tetragonal symmetry using conventional x-ray diffractometers. Becatse the pronounced broadening of X ray peak at about $45^{\circ}$, which are attributed to the small particle size of $\mathrm{BaTiO}_{3}$ crystals, Because nanoparticles cause the peak line broadening and results in thus the peak splitting is hidden [19], it is diffieult to assign the crystal structure of $\mathrm{BaTiO}_{3}$ to either cubic or tetragonal symmetry, although no obvious splitting of the $(200) /(002)$ diffraction peaks is observed from XRD pattern.

It is well known that Raman spectroscopy is a useful technique for probing the phase structure of the $\mathrm{BaTiO}_{3}$ nanoparticles at the atomic scale, on the basis of vibrational symmetry. Cubic phase $\mathrm{BaTiO}_{3}$ inherently has no Raman active modes because of the isotropic distribution of the electrostatic forces, however Raman active modes are expected for the noncentrosymmetric tetragonal structure [23]. The bands at 183, 247, 305, 514, and $715 \mathrm{~cm}^{-1}$ observed in Fig. 1(b), are attributed to the A1 (LO), A1 (TO), $\mathrm{B} 1+\mathrm{E}(\mathrm{TO}+\mathrm{LO}), \mathrm{E}(\mathrm{TO})+\mathrm{A} 1(\mathrm{TO})$, and the $\mathrm{A} 1(\mathrm{LO})+\mathrm{E}(\mathrm{LO})$ modes respectively, which is typical tetragonal structure [18]. These results indicate that the obtained $\mathrm{BaTiO}_{3}$ nanocubeids are whether single phase of tetragonality or mixed phase of cube and tetragonality.

Scanning electron microscopy (SEM) and TEM are powerful techniques for morphology 
characterization. SEM image has not been obtained due to the too small size of nanoparticles to be clearly observed by our low resolution scanning electron microscope. As shown in Fig. 1c, The TEM images (Fig. 1c ) reveal that the products are cuboid shaped nanoparticles and well-dispersed without aggregation. In addition, a uniform diffraction contrast across these single crystals is also observed, indicating that the crystals have a low strains. SADE pattern (Fig. 1d) recorded on these particles shows polycrystalline diffraction rings with discrete diffraction spots, which can be ascribed to either cubic or tetragonal $\mathrm{BaTiO}_{3}$. Although the crystallite size calculated from XRD is around $20 \mathrm{~nm}$, the particle size distribution (Fig. 1e) derived from TEM image shows an average particle size of $13.5 \mathrm{~nm}$ along the longer edge of $\mathrm{BaTiO}_{3}$ nanocuboids. HRTEM (Fig. 1f) shows that $\mathrm{BaTiO}_{3}$ nanocuboid possesses $\{100\}$ faceted edges and is free of defects such as stacking faults and dislocations. The measured fringe spacing is $0.40 \mathrm{~nm}$, which is corresponded to the (100) and (010) lattice spacing of cubic $\mathrm{BaTiO}_{3}[18]$, indicating that some of $\mathrm{BaTiO}_{3}$ nanocuboids have perovskite cubic phase. The fast Fourier transform(FFT) pattern (Fig. 1g) of HRTEM further demonstrates that the exposed surface belongs to the (001) plane of $\mathrm{BaTiO}_{3}$. The images of TEM and HRTEM and the FFT pattern are well agreement with the literatures [14], and suggesting that $\mathrm{BaTiO}_{3}$ nanocuboids have been successfully prepared. Hence Moreover, according to the results of HRTEM, XRD and Raman spectrum, it can be drawn that the obtained $\mathrm{BaTiO}_{3}$ nanocuboids are mixed phase of cube and tetragonality.

For $\mathrm{BaTiO}_{3}$ nanocrystals prepared with $\mathrm{OA}$ as surfactant, it can be found that $\mathrm{OA}$ molecules molectlars are generally absorbed adsorbed on their nanocrystal surfaces [21]. Fig. 2a shows FT-IR spectra of the $\mathrm{BaTiO}_{3}$ nanocrystals prepared with and without OA, respectively. The FT-IR peaks ranging from 3200 to $3500 \mathrm{~cm}^{-1}$ can be ascribed to $\mathrm{H}_{2} \mathrm{O}$ adsorbed by surface-hydroxyl groups of $\mathrm{BaTiO}_{3}$ crystals-the surface-hydroxy adsorbed water or $\mathrm{OH}$ defects in $\mathrm{BaTiO}_{3}$ crystals. The peaks ranging from 2925 to 2858 $\mathrm{cm}^{-1}$ belonging to the $\mathrm{C}-\mathrm{H}$ stretching mode of methyl and methylene groups are observed in both cases of 
$\mathrm{OA}$ and $\mathrm{BaTiO}_{3}$ nanocrystals prepared with $\mathrm{OA}$. Instead of the appearance of $\mathrm{C}=\mathrm{O}$ stretching vibration at $1718 \mathrm{~cm}^{-1}$ in case of OA itself, two characteristic peaks at 1558 and $1432 \mathrm{~cm}^{-1}$ associated with asymmetric and symmetric COO-stretching vibrations are found in the spectrum of $\mathrm{BaTiO}_{3}$ nanocrystals prepared with $\mathrm{OA}$, evidently indicating that the chemical bonds between the surface of $\mathrm{BaTiO}_{3}$ nanocrystals and $\mathrm{OA}$ are formed $[14,24]$.

Compared with the static contact angle image between Fig. $2 \mathrm{~b}$ and $2 \mathrm{c}$, it is clearly observed that the water contact angle on the thin film compressed with $\mathrm{BaTiO}_{3}$ nanocrystals, which were prepared with $\mathrm{OA}$, is $117.9^{\circ}$. In contrast, in the case of without OA, the contact angle dramatically decreased to $14.5^{\circ}$. This result indicates that the $\mathrm{OA}$ molecules exist on the external surface of $\mathrm{BaTiO}_{3}$ and convert the hydrophilic surface of $\mathrm{BaTiO}_{3}$ to a hydrophobic one.

TG curve (Fig. 2d) further demonstrates the presence of OA molecules on the surface of $\mathrm{BaTiO}_{3}$ nanocrystals. Except for the weight loss of approximately $2.6 \%$ before $250{ }^{\circ} \mathrm{C}$ deriving from the adsorbed water or the $\mathrm{OH}$ defects in crystals [25], the other two weight loss steps ranging from 250 to $550{ }^{\circ} \mathrm{C}$ are attributed to the releases of OA molecules attaching on the outer and inner surface layers of $\mathrm{BaTiO}_{3}$ nanocrystals, respectively [26], as shown in the suggested OA adsorption model in Fig. 2d. Moreover, the total amount of OA is high to $23 \mathrm{wt} \%$, which should be important in controlling the particle size and the monodispersity of $\mathrm{BaTiO}_{3}$ nanocrystals.

\subsection{Reproducibility of preparation of $\mathrm{BaTiO}_{3}$ nanocuboids}

It is known that some reported experiments with microwave heating technology are difficult to be repeated and compared by other researchers. The reason behind this phenomenon has been pointed out by Zhu et al in their review article [27], that is, the microwave oven is not in the same type for different laboratories, which causes the variance in heating/cooling rate, measuring and controlling the temperature, and thus the low reproducibility. In this work, a commercial research-type microwave oven with one 
sample-tube was used, which can operate in temperature control mode under autogenous pressure. Although $\pm 1{ }^{\circ} \mathrm{C}$ of precise temperature control can be realized in range of $0-250{ }^{\circ} \mathrm{C}$, the heating rate is uncontrollable.

In order to investigate the reproducibility of preparation of $\mathrm{BaTiO}_{3}$ nanocuboids with microwave heating, four repeated experiments have been carried out with precursor of $\mathrm{Ba}(\mathrm{OH})_{2}: 0.83 \mathrm{Ti}(\mathrm{OBu})_{4}: 0.3$ OA: $394 \mathrm{H}_{2} \mathrm{O}$ at $200{ }^{\circ} \mathrm{C}$ for $4 \mathrm{~h}$, and the morphology of the products are characterized by TEM. Just as shown in Fig.3, these products have similar morphology and are mainly nanocuboid shape, suggesting a good reproducibility.

\subsection{Effects of synthesis parameters}

\subsubsection{Effect of $\mathrm{H}_{2} \mathrm{O} / \mathrm{Ba}$ and $\mathrm{OA} / \mathrm{Ba}$ molar ratio.}

In order to clarify the role of water in the formation of $\mathrm{BaTiO}_{3}$ nanocuboids, the molar ratio of $\mathrm{H}_{2} \mathrm{O} / \mathrm{Ba}$ was varied from 99 to 495 (Table 1), and the XRD patterns and TEM images of the resultant products are shown in Fig. 3. Independent of the molar ratio of $\mathrm{H}_{2} \mathrm{O} / \mathrm{Ba}$, all the XRD patterns demonstrate that the resultant $\mathrm{BaTiO}_{3}$ have perovskite structures. TEM images show that the particle size of $\mathrm{BaTiO}_{3}$ nanoparticles slightly increases with the increase of $\mathrm{H}_{2} \mathrm{O} / \mathrm{Ba}$ molar ratio, and in all the cases the particle sizes are less than $20 \mathrm{~nm}$. In addition, the number of $\mathrm{BaTiO}_{3}$ nanocrystals with cuboid shape gradually increases with the increase of the molar ratio of $\mathrm{H}_{2} \mathrm{O} / \mathrm{Ba}$. In case of $\mathrm{H}_{2} \mathrm{O} / \mathrm{Ba}$ ratio of 99 , the nanoparticles mainly are nearly spherical apart from few cubic shapes. This can be attributed to the high concentration of $\mathrm{OA}$, which weakens the selective adsorption of $\mathrm{OA}$ on special faces of $\mathrm{BaTiO}_{3}$ nanocrystals. $\mathrm{As}_{2} \mathrm{O} / \mathrm{Ba}$ ratio increasing to 197,395 and 495, OA concentration decreases gradually, and they are preferentially adsorbed on the crystal planes with higher surface energy, thus controlling the morphology of nanocrystals. Just as shown in Fig.3b-3d4b-4d, in which the main morphology is cubic. Especially in Fig.34c, nearly $90 \%$ of the nanoparticles exhibit the cuboid shapes. 
To further test the effect of $\mathrm{OA}$ concentration on the morphology of $\mathrm{BaTiO}_{3}$ nanocrystals, the molar ratio of $\mathrm{OA} / \mathrm{Ba}$ was varied under the condition of fixed other synthesis parameters.

XRD patterns (Fig. 45a) show that the intensity of all the diffraction peaks dramatically decreases and the half height width increases with increasing the molar ratio of $\mathrm{OA} / \mathrm{Ba}$ in precursor. When the $\mathrm{OA} / \mathrm{Ba}$ molar ratio increases up to 1.09 the diffraction peaks nearly disappear. A reasonable explanation for this phenomenon as follows. OA can not only reacts with titanium to form the complex [27 28] but also damages the alkalinity of synthesis system, leading to a reduced concentration of active monomer of $\left[\mathrm{TiO}_{6}\right]^{8-}[2829]$ and then to a low degree of super saturation [29 30]. Hence, it is difficult for nanocrystal to grow into the large particles due to lack of active monomer as nutrient. Furthermore, once the nuclei form in synthesis system, the excess OA can cap them rapidly and then reduce their growth rate, too. Therefore, the particle size of $\mathrm{BaTiO}_{3}$ nanocrystal decreases with the increase of $\mathrm{OA} / \mathrm{Ba}$ molar ratio. TEM images (Fig. $4 b-4(5 b-5 d)$ also proved this opinion.

In addition, the effect of oleic acid on the morphology of $\mathrm{BaTiO}_{3}$ nanoparticles was clearly shown in TEM images (Fig. 5 b-5e). Without addition of OA there was no cuboid shaped $\mathrm{BaTiO}_{3}$ nanoparticles [21] (Fig. 45b), and well defined $\mathrm{BaTiO}_{3}$ nanocuboids can be obtained in the range of $0.3-0.5$ of $\mathrm{OA} / \mathrm{Ba}$ molar ratio (Fig. $4 c-4 d 5 c-5$ d). However, further increasing OA/Ba molar ratio to 0.83 (Fig. 45e), only the nearly spherical torispherical $\mathrm{BaTiO}_{3}$ nanoparticles with smaller size were observed. This result confirmed further that the excessive $\mathrm{OA}$ in precursor solution were not only adsorbed preferentially on special crystal faces of $\mathrm{BaTiO}_{3}$ nanocrystals, but also absorbed adsorbed on other crystal faces, and resulting in spherical $\mathrm{BaTiO}_{3}$ nanoparticles.

\subsubsection{Effect of Ba/Ti molar ratio and barium source}

Some researchers [30-3131-32] suggest that increasing Ba/Ti molar ratio in precursor favors to form the frame cubic growth units, and these growth units are easy to pile up on the faces of the same equiaxial 
family equiaxially along the three crystal axes, and thus to form $\mathrm{BaTiO}_{3}$ crystal with cubic shape. To obtain $\mathrm{BaTiO}_{3}$ nanocrystals with more uniform morphology, $\mathrm{Ba} / \mathrm{Ti}$ molar ratio in precursor is increased from 1:0.83 to1.66:0.83. However, TEM images (Fig. 56b) give unexpected results. Instead of regular cuboid shape, irregular shapes are obtained, although the perovskite structure of the product has no change (Fig. 56a). According to literature [3132], the main function of $\mathrm{Ba}^{2+}$ ions is stabilizing the growth units of $\left[\mathrm{TiO}_{6}\right]^{8-}$ octahedral. The more the $\mathrm{Ba}^{2+}$ ions are absorbed-adsorbed, the higher the stability energy of the growth unit becomes, and the easier the cube shaped $\mathrm{BaTiO}_{3}$ forms. In this work, with increasing $\mathrm{Ba} / \mathrm{Ti}$ molar ratio, a different result from literature has been obtained, why? In fact, it should be noted that the alkalinity in precursor is increased accompanying with the increase of $\mathrm{Ba} / \mathrm{Ti}$ molar ratio due to the addition of $\mathrm{Ba}$ ions in the form of $\mathrm{Ba}(\mathrm{OH})_{2}$, and the synthesis system with high alkalinity usually produced nearly spherical torispherical $\mathrm{BaTiO}_{3}$ nanoparticles [32 33]. In order to eliminate the effect of alkalinity, the total $\mathrm{Ba} / \mathrm{Ti}$ molar ratio is fixed at 1.66:0.83, and $\mathrm{Ba}(\mathrm{OH})_{2}$ is partly replaced with $\mathrm{BaCl}_{2}$ or $\mathrm{BaNO}_{3}$ by a fixed $\mathrm{Ba} / \mathrm{Ti}$ molar ratio of 1.66:0.83. The final molar ratio of $\mathrm{Ba}(\mathrm{OH})_{2}: \mathrm{BaCl}_{2}\left(\right.$ or $\left.\mathrm{BaNO}_{3}\right)$ : Ti is kept at of 1:0.66:0.83.

TEM images demonstrate that cuboid shape can be well maintained in the case of $\mathrm{Ba}(\mathrm{OH})_{2}: \mathrm{BaCl}_{2}: \mathrm{Ti}$ molar ratio of 1:0.66: 0.83(Fig. 56e), which is contrast to the case of $\mathrm{Ba}(\mathrm{OH})_{2}: \mathrm{Ti}=1.66: 0.83$ (Fig. 56b). Hence, it is drawn that the shape conversion observed from Fig 56a and Fig 56 b is caused by the change of alkalinity in precursor instead of the molar ratio of $\mathrm{Ba} / \mathrm{Ti}$. However, in the case of $\mathrm{Ba}(\mathrm{OH})_{2}: \mathrm{Ba}\left(\mathrm{NO}_{3}\right)_{2}: \mathrm{Ti}$ molar ratio of 1:0.66: 0.83, some irregular shapes (Fig 56c) are found, indicating that the anion species have an influence on $\mathrm{BaTiO}_{3}$ nanocrystal shape. $\mathrm{Ni}$ et al [3334] also found that the barium source could affect the morphology $\mathrm{BaTiO}_{3}$ nanostructures. Under their synthesis condition, coral-like $\mathrm{BaTiO}_{3}$ nanostructures, aggregated $\mathrm{BaTiO}_{3}$ nanoparticles/rods, and the coexistence of coral-like nanostructures/big grains were obtained in cases of $\mathrm{BaCl}_{2}, \mathrm{Ba}\left(\mathrm{CH}_{3} \mathrm{COO}\right)_{2}$ and $\mathrm{Ba}\left(\mathrm{NO}_{3}\right)_{2}$ as barium source, respectively. The 
authors suggested that the stronger coordinative ability $\mathrm{CH}_{3} \mathrm{COO}^{-}$with $\mathrm{BaTiO}_{3}$ nuclei, the occupation of small amounts of active sites on $\mathrm{BaTiO}_{3}$ nuclei by $\mathrm{Cl}^{-}$or $\mathrm{NO}_{3}{ }^{-}$ions resulted in different morphology of $\mathrm{BaTiO}_{3}$. Dutta et al investigated the influence of barium source in hydrothermal system [3435]. Their results indicated that the anions (such as $\mathrm{Cl}^{-}$and $\mathrm{NO}_{3}^{-}$) of barium source influenced the phase structure of $\mathrm{BaTiO}_{3}$, but did not affect the morphology. Torispherical Nearly spherical $\mathrm{BaTiO}_{3}$ nanoparticles were obtained in all their studied cases. Due to differences in experimental conditions with the literatures, $\mathrm{Cl}^{-}$ obviously helped to the formation of cuboid shaped $\mathrm{BaTiO}_{3}$ nanoparticles compared with $\mathrm{NO}_{3}{ }^{-}$in this work. We speculated that $\mathrm{Cl}^{-}$could be adsorbed much more strongly on (010) crystal plane of $\mathrm{BaTiO}_{3}$ than $\mathrm{NO}_{3}{ }^{-}$. Under synergetic effects of $\mathrm{Cl}^{-}$and $\mathrm{OA}$, cuboid shaped $\mathrm{BaTiO}_{3}$ nanoparticles are obtained. So, it seems that the important factor influencing the morphology of $\mathrm{BaTiO}_{3}$ is the anion type of barium source rather than the $\mathrm{Ba} / \mathrm{Ti}$ molar ratio.

\subsubsection{Effect of synthesis temperature and time}

It is known that the high temperature and prolonged time can accelerate the formation of $\mathrm{BaTiO}_{3}$ under hydrothermal conditions. In our work, the XRD patterns in Fig. 67a indicate that the synthesis temperature varying in the range of $140-200{ }^{\circ} \mathrm{C}$ has little effect on the perovskite structure of $\mathrm{BaTiO}_{3}$ nanocrystals. But TEM images suggest that the shape of $\mathrm{BaTiO}_{3}$ nanocrystals remarkably changes with temperature. No cuboid shape but irregular sphere can be obtained when temperature is below $160{ }^{\circ} \mathrm{C}$ (Fig. $67 \mathrm{~b}$ and $67 \mathrm{c}$ ). Compared with the case of $180{ }^{\circ} \mathrm{C}$ (Fig. $67 \mathrm{~d}$ ), the number of $\mathrm{BaTiO}_{3}$ nanocuboids obviously increase when synthesis temperature is up to $200{ }^{\circ} \mathrm{C}$ (Fig. 67 e). It can be concluded that high temperature is helpful for the formation of $\mathrm{BaTiO}_{3}$ nanocuboids.

The synthesis time is varied from $2 \mathrm{~h}$ to $6 \mathrm{~h}$ at a fixed temperature of $200{ }^{\circ} \mathrm{C}$. XRD patterns (Fig. 67a) show that the intensity of diffraction peaks has little change with time, suggesting that the crystallization speed of $\mathrm{BaTiO}_{3}$ nanocrystals is very fast under microwave irradiation and the crystallization process 
nearly completes in $2 \mathrm{~h}$. TEM images (Fig. $67 \mathrm{e}-7 \mathrm{~h}$ ) also prove that the $\mathrm{BaTiO}_{3}$ nanocuboids have been formed at $2 \mathrm{~h}$, and further increasing the synthesis time to $5 \mathrm{~h}$ has little effect on the morphology. However, Fig. 67i shows that most of $\mathrm{BaTiO}_{3}$ nanocuboids lose their shape and become to be spherical when the synthesis time was prolonged to $6 \mathrm{~h}$, although the XRD diffraction intensity of this sample is comparative with that of $5 \mathrm{~h}$. A reasonable explanation is that a dissolution-recrystallization process maybe occurs when the $\mathrm{BaTiO}_{3}$ nanocuboids are heated in their alkalie alkaline mother liquor for prolonged time. And thus the spherical $\mathrm{BaTiO}_{3}$ nanocrystals with size of $10-15 \mathrm{~nm}$ may be the remnants of $\mathrm{BaTiO}_{3}$ nanocuboids after partly dissolving, and those with small size $(<10 \mathrm{~nm})$ are new-formed by recrystallization.

\subsubsection{Growth mechanism of the $\mathrm{BaTiO}_{3}$ nanocuboids}

To investigate the formation and shape evolution of $\mathrm{BaTiO}_{3}$ nanocuboids, time-dependent experiments were carried out and the products collected at different stages were analyzed by XRD, TEM and HRTEM (Fig.78). The XRD patterns of the samples synthesized for 5, 10, 15 and 30 min are inserted in the corresponding TEM images. Obviously, except of the presence of little amount of $\mathrm{BaCO}_{3}$, the products are single perovskite in structure. The intensity of the diffraction peaks increases with prolonging the reaction time, which imply the growing particle size and better crystallinity of $\mathrm{BaTiO}_{3}$ nanocrystals [35 36].

TEM image in Fig. 78a shows that the solid quenched at 5 min are aggregated particles with irregular shape and wide size distribution. The large particles (Fig. $78 \mathrm{c}$ ) are amorphous, which should be $\mathrm{TiO}_{2}$ or barium oleate gels formed in the process of precursor preparation. However, the small particles with size less than $10 \mathrm{~nm}$ are fully crystallized and single-crystal in nature (Fig. 78b). In case of $10 \mathrm{~min}$ (Fig. $78 \mathrm{~d}$ ), the particle aggregation is slightly weakened and the average particle size reduces. Compared with the case of $5 \mathrm{~min}$, the number and size of nanocrystals (Fig. $7 \mathrm{~d}-7 \mathrm{e} 8 \mathrm{~d}-8 \mathrm{e}$ ) increase. In addition, the sizes of amorphous particles (Fig. 78f) reduced, too. These phenomena indicate that the growth of $\mathrm{BaTiO}_{3}$ follows the dissolution-crystallization mechanism [36 37]. 
When synthesis time is prolonged to $15 \mathrm{~min}$, the amorphous particles disappear due to complete dissolution, and the obtained particles with irregular morphology are monodispersed and crystallized (Fig. 7g-7i8g-8i). Prolonging time to $30 \mathrm{~min}$, the particle size slightly increases and small nanocrystals disappear (Fig. 78j), which results from the Ostwald ripe mechanism. In addition, more and more particles exhibit cubic or cuboid shape. The distinct and consistent lattice fringes observed from HRTEM images (Fig. 78k and 781) suggest a better crystalline of these particles.

According to the research of Wei et al [37 38], to minimize the surface area, $\mathrm{BaTiO}_{3}$ particles remain approximately spherical shape in the early stage of crystal growth. And then, following crystallographic growth causes the spherical shape to develop into cube shape due to the lowest energy of the $\left\{\begin{array}{lll}1 & 0 & 0\end{array}\right\}$ planes. But the faceted edges of $\left\{\begin{array}{lll}1 & 0 & 0\end{array}\right\}$ planes are high energy and are subjected to preferential dissolution, leading to a final morphology of spherical shape. In this work, OA molecules existing in synthesis system should be absorbed adsorbed on these high energy edges and thus stabilize the cube or cuboid shape of $\mathrm{BaTiO}_{3}$. A similar result is reported by Adireddy et al [19], although their synthesis conditions are different from this work.

On the basis of morphological features observed in the present study, a growth mechanism of the $\mathrm{BaTiO}_{3}$ nanocuboids is proposed, where the formation of $\mathrm{BaTiO}_{3}$ nanocuboids is governed by the dissolution crystallization mechanism, followed by the Ostwald ripening process in which the lowest energy of the planes are exposed and the high-energy faceted edges are stabilized by-absorbing adsorbing OA molecules, and thus the cuboid morphology is preserved.

\subsubsection{Photocatalytic property of $\mathrm{BaTiO}_{3}$ nanocudoids}

It is known that $\mathrm{BaTiO}_{3}$ is an insulator with a large energy gap. Suzuki et al [38] revealed that the particle size of $\mathrm{BaTiO}_{3}$ nanocrystallites nanocrystals has influence on the band gap, and the indirect band gap is in the range of 3.22-3.28 eV for $\mathrm{BaTiO}_{3}$ nanocrystals with sizes of 11.5-15.3 nm. In this work, the 
direct and indirect optical band gaps of $\mathrm{BaTiO}_{3}$ nanocubiods prepared with the precursor molar composition of $\mathrm{Ba}(\mathrm{OH})_{2}: 0.83 \mathrm{Ti}: 0.3 \mathrm{OA}: 394 \mathrm{H}_{2} \mathrm{O}$ at $200{ }^{\circ} \mathrm{C}$ for $4 \mathrm{~h}$ are $3.75 \mathrm{eV}$ and 3.15 (inset of Fig. 89a), respectively, which are calculated using the equations of Kubelka-Munk based on UV-Vis diffuse reflectance spectrum (Fig. 89a). The size of $\mathrm{BaTiO}_{3}$ nanocubiods obtained in this work is about $13 \mathrm{~nm}$, so the indirect band gap of $3.15 \mathrm{eV}$ is more reasonable and seems to be the preferred one. In addition, this value is in agreement with literature result [19] where a band gap $3.2 \mathrm{eV}$ is gotten for cube shaped $\mathrm{BaTiO}_{3}$ nanocrystals with size of about $22 \mathrm{~nm}$.

From the calculated band gap of $3.15 \mathrm{eV}$ ev, it is deduced that $\mathrm{BaTiO}_{3}$ nanocudoids should possess photocatalytic activity. And thus, the experiment of $\mathrm{RhB}$ photodegradation was carried out under UV light irradiation as a model reaction. Because adsorption of $\mathrm{RhB}$ molecules on catalyst is an important step in the decolorization process, prior to exposure UV light irradiation, the time getting to the stable adsorption equilibrium situation in dark is measured. The results are shown inset of Fig. 89b. It is clearly observed that the adsorption amount of $\mathrm{RhB}$ increase with increasing the amount of catalyst. But the time getting to the adsorption equilibrium is independent on the amount of catalyst and is about $30 \mathrm{~min}$. So, the photocatalysis photocatslysis experiment is started after the solution has been stirred for 30 min in dark.

Fig. 89b shows the photodegradation photogradation efficiency of $\mathrm{RhB}$ with different amount of $\mathrm{BaTiO}_{3}$ nanocuboids for different exposure time. As the exposure time increases, the degradation of $\mathrm{RhB}$ also increases. After UV irradiation $220 \mathrm{~min}, \mathrm{RhB}$ degradation has completed. It is noted that the degradation rate decreases with catalyst amount increasing from 10,20,40,60 mg, the possible reason is that the excess catalysts enhance light scattering, which results in a reduced light utilization [39 40]. Fixing the catalyst at $10 \mathrm{mg}$, the effect of RhB concentration is investigated. As shown in Fig. 89c, the degradation rate decreases with the increase of $\mathrm{RhB}$ concentration. When the concentration of $\mathrm{RhB}$ is $5 \mathrm{mg} / \mathrm{L}$, the fastest degradation rate is achieved, and nearly complete degradation is gotten at $180 \mathrm{~min}$, which is proved by the inset of Fig. 
$89 \mathrm{c}$.

There are few studies on the photo degration degradation of $\mathrm{RhB} \mathrm{Rh} \mathrm{B}$ with $\mathrm{BaTiO}_{3}$ as catalyst eatalytst, and their results are listed in Table 2. Recently, some researches show that $\mathrm{BaTiO}_{3}$ with tetragonal phase exhibits better photocatalytic performance than the cubic phase due to the ferroelectricity promoting the carrier separation and stern layer formation [45]. However, the degradation efficiency of $\mathrm{RhB} R \mathrm{Rh} B$ in Table 2 is remarkably different, although all the $\mathrm{BaTiO}_{3}$ used in literature [40 41], [4142] and [4] have the same crystal structure. So, the ferroelectricity should not be the key factor to determine the photocatalytic activity of $\mathrm{BaTiO}_{3}$, if without considering the influence of other experiment parameters. In fact, the dipolar fields associated with the ferroelectric domains in small particles can separate photo-generated charge carriers and spatially localize reaction products, which results in the relative reactivity of the faces is different [46]. But for literatures [4041], [4142] and this work, the exposed faces of $\mathrm{BaTiO}_{3}$ nanocrystals are the same type of $\{100\}$, indicating that the main factor influencing the photocatalytic activity of $\mathrm{BaTiO}_{3}$ is not the exposed face. In addition, it is known that particle sizes of a catalyst have a significant impact on the catalytic efficiency of a system [43]. When all other conditions are equal, it is anticipated that a smaller particle size will lead to better catalytic performance, due to a larger surface area with more active sites and a shorter migrating time of photoexcited electrons from the inner to surfaces [44]. Although there is no a linear relationship between particle size and $\mathrm{RhB} R \mathrm{Rh} \mathrm{B}$ degradation efficiency in Table 2, a general trend can still be derived, that is, $\mathrm{BaTiO}_{3}$ with size less than $20 \mathrm{~nm}$ represents a relatively high photocatalytic activity. However, compared with the $7.5 \mathrm{~nm} \mathrm{BaTiO}_{3}$ nanoparticles with pure tetragonal phase (Table 2), the $\mathrm{BaTiO}_{3}$ nanocuboids prepared in our work exhibit much higher photo catalytic activity, even though they have larger size and are a mixture of tetragonal and cubic phase. A possible reason is that the amount of $\mathrm{BaTiO}_{3}$ added into $\mathrm{RhB} \mathrm{Rh} \mathrm{B}$ solution is too much in literature $\left(1 \mathrm{~g} \cdot \mathrm{L}^{-1}\right)$ than this work $\left(0.3 \mathrm{~g} \cdot \mathrm{L}^{-1}\right)$, which results in stronger light scattering, and then lower the light utilization efficiency, just as observed in Fig. 
89b. Based on the above, the high degradation efficiency of $\mathrm{RhB} \mathrm{Rh} \mathrm{B}$ obtained in this work is mainly attributed to the small size and the appropriate dosage of $\mathrm{BaTiO}_{3}$ nanocuboids. Certainly, the contribution of the exposed $\{100\}$ planes and the ferroelectricity ean not cannot be ignored.

\subsection{Role of $O A$ in photocatalysis}

In fact, the adsorbed $\mathrm{OA}$ on the surface of $\mathrm{BaTiO}_{3}$ nanocuboids may play a role in the photocatalysis process. In order to figure out its function, $\mathrm{OA}$ is burned off in muffle oven at $500{ }^{\circ} \mathrm{C}$ for $2 \mathrm{~h}$. This treatment results in a remarkable increase of particle size (Fig.10a), and thus losing the qualification as a reference in comparative experiment. And then, we have tried to remove OA away by repeated washing with ethanol. This treatment causes severe agglomeration, but has little influence on the particle size (Fig.10b). IR results (Fig.10c) show that the adsorption bands attributing to OA at 2925,2858 and $1558 \mathrm{~cm}^{-1}$ have almost disappeared after ethanol washing, meaning that most of OA have been washed away from the surface of $\mathrm{BaTiO}_{3}$ nanoparticles. Although both the photocatalytic activity and the adsorption for RhB in the dark are lower compared to the untreated $\mathrm{BaTiO}_{3}$ (Fig. 10d), attributing it to the loss of OA is arbitrary, because the effective surface area also decreases due to the severe agglomeration, which should not be neglected in evaluation of photocatalytic activity. And thus, it is necessary to develop effective method of removing OA and preventing aggregation, and some work is proceeding.

\section{Conclusions}

Monodispersed $\mathrm{BaTiO}_{3}$ nanocuboids are prepared by microwave hydrothermal methods at $200{ }^{\circ} \mathrm{C}$ for 4 h. The synthesis parameters, such as temperature, time, and molar ratio in the precursor mixture, have great influence on the shape, crystalline and aggregation of $\mathrm{BaTiO}_{3}$ nanocrystals. The achieved $\mathrm{BaTiO}_{3}$ nanocuboids are consisted of cubic and tetragonal phases and show high hydrophobic surface property. Based on TEM images of solid extracted from the synthesis system quenched at different time, it is drown that the growth of $\mathrm{BaTiO}_{3}$ nanocuboids follows the dissolution-recrystallization mechanism and the 
Ostwald ripening process, in which the OA molecules molectlar play important role in controlling the shape of $\mathrm{BaTiO}_{3}$ nanocrystals. Compared with literatures, the present $\mathrm{BaTiO}_{3}$ nanocuboids exhibit higher photocatalytic activity for RhB degradation under UV irradiation. Nearly complete degradation can be achieved in $180 \mathrm{~min}$ for $5 \mathrm{~mol} / \mathrm{L} \mathrm{RhB}$ solution.

\section{Acknowledges}

The authors would like to thank Key Technologies R\&D Program of Shaanxi Province (2012K08 09, 2014K10-06, 2015XT-18), National Science Foundation Committee of China (51373092, 21543012), Natural Science Foundation of Shaanxi Province (2012JM2002, 2014JM7270), Specialized Research Fund for the Doctoral Program of Higher Education (20130202120010), the Fundamental Research Funds for the Central Universities (GK201503038201101003, GK201302036, GK201302037), Program for Key Science \& Technology Innovation Team of Shaanxi Province (2012KCT-21) for financial support of this work.

\section{References}

[1] J.F.Scott. Applications of modern ferroelectrics, Science 315(5814) (2007) 954-959.

[2] C. Pithan, D. Hennings, R.Waser. Progress in the synthesis of nanocrystalline $\mathrm{BaTiO}_{3}$ powders for MLCC, Int. J. Appl. Ceram. Tec. 2(1) (2005) 1-14.

[3] E. Kim, A. Steinbrück, M.T. Buscaglia, V. Buscaglia, T. Pertsch, R.Grange, Second-harmonic generation of single $\mathrm{BaTiO}_{3}$ nanoparticles down to $22 \mathrm{~nm}$ diameter, ACS Nano. 7(6) (2013) $5343-5349$.

[4] H. Fan, H. Li, B. Liu, Y. Lu, T. Xie, D.Wang, Photoinduced charge transfer properties and photocatalytic activity in $\mathrm{Bi}_{2} \mathrm{O}_{3} / \mathrm{BaTiO}_{3}$ composite photocatalyst, ACS Appl. Mater. Interfaces. 4(9) (2012) 4853-4857.

[5] W. Wang, H. Yang, T. Xian, R. Li, J. Ma, J.Jiang, Photocatalytic degradation of methyl red by $\mathrm{BaTiO}_{3}$ nanoparticles via a direct hole oxidation mechanism, Adv. Sci. Eng. Med. 4(6) (2012) 479-483.

[6] W. W. Lee, W. H. Chung, W. S. Huang, W. C Lin, W. Y Lin, Y. R. Jiang, C. C Chen, Photocatalytic activity and mechanism of nano-cubic barium titanate prepared by a hydrothermal method, J. Taiwan 
Inst. Chem. Eng. 44(4) (2013) 660-669.

[7] J. Liu, Y. Sun, Z. Li, Ag loaded flower-like $\mathrm{BaTiO}_{3}$ nanotube arrays: Fabrication and enhanced photocatalytic property, Cryst. Eng. Comm. 14(4) (2012) 1473-1478.

[8] Y. Cui, J. Briscoe, S. Dunn, Effect of ferroelectricity on solar-light-driven photocatalytic activity of $\mathrm{BaTiO}_{3}$ influence on the carrier separation and stern layer formation, Chem. Mater. 25(21) (2013) 4215-4223.

[9] K. C. Huang, T. C. Huang, W. F. Hsieh, Morphology-controlled synthesis of barium titanate nanostructures, Inorg. Chem. 48(19) (2009) 9180-9184.

[10] M. M. Kržmanc, I. Bračko, B. Budič, D. Suvorov, The morphology control of $\mathrm{BaTiO}_{3}$ particles synthesized in water and a water/ethanol solvent, J. Am. Chem. Soc. 96(11) (2013) 3401-3409.

[11] J. Y. Son, J. H. Lee, S. Song, Y. H. Shin, H. M. Jang, Four-states multiferroic memory embodied using Mn-doped $\mathrm{BaTiO}_{3}$ nanorods, ACS nano. 7(6) (2013) 5522-5529.

[12] Y. Yang, X. Wang, C. Sun, L. Li, Structure study of single crystal $\mathrm{BaTiO}_{3}$ nanotube arrays produced by the hydrothermal method, Nanotechnology. 20(5) (2009) 055709.

[13] J. Yang, J. Zhang, C. Liang, M. Wang, P. Zhao, M. Liu, J. Liu, R. Chen, Ultrathin $\mathrm{BaTiO}_{3}$ nanowires with high aspect ratio: a simple one-step hydrothermal synthesis and their strong microwave absorption, ACS Appl. Mater. Interfaces. 5(15) (2013)7146-7151.

[14] a) F. Dang, K. Mimura, K. Kato, H. Imai, S. Wada, H. Haneda, M. Kuwabara, In situ growth $\mathrm{BaTiO}_{3}$ nanocubes and their superlattice from an aqueous process, Nanoscale. 4(4) (2012) 1344-1349; b) Q. Ma, K. Mimura, K. Kato, Diversity in size of barium titanate nanocubes synthesized by a hydrothermal method using an aqueous Ti compound, CrystEngComm. 16(36) (2014) 8398-8405; c) Q. Ma, K. Mimura, K. Kato, Size and morphology controlling of barium titanate nanocubes by using hydrothermal method, J. Korean Phys. Soc. 66(9) (2015) 1364-1366; d) Q. Ma, K. Mimura, K. Kato, Tuning shape of barium titanate nanocubes by combination of oleic acid/tert-butylamine through hydrothermal process, J. Alloy. Compd. 655(15) (2016) 71-78;

[15] K. Mimura, K. Kato, H. Imai, S. Wada, H. Haneda, M. Kuwabara, Piezoresponse properties of orderly assemblies of $\mathrm{BaTiO}_{3}$ and $\mathrm{SrTiO}_{3}$ nanocube single crystals, Appl. Phys. Lett. 101(1) (2012) 012901-012904.

[16] B. Hou, Z. Li, Y. Xu, D. Wu, Y. Sun, Solvothermal synthesis of single-crystalline $\mathrm{BaTiO}_{3}$ nanocubes in a mixed solution, Chem. Lett. 34(7) (2005) 1040-1041. 
[17] T. Yan, Z. Shen, J. Chen, X. Liu, X. Tao, J. Yun, Synthesis of well-isolated barium titanium trioxide nanocubes, Chem. Lett. 34(8) (2005) 1196-1197.

[18] H. Liu, C. Hu, Z. Wang, Composite-hydroxide-mediated approach for the synthesis of nanostructures of complex functional-oxides, Nano lett. 6(7) (2006) 1535-1140.

[19] S. Adireddy, C. Lin, B. Cao, W. Zhou, G. Caruntu, Solution-based growth of monodisperse cube-like BaTiO3 colloidal nanocrystals, Chem. Mater. 22(6) (2010) 1946-1948.

[20] S. Wada, A. Nozawa, M. Ohno, H. Kakemoto, T. Tsurumi, Y. Kameshima, Y. Ohba, Preparation of barium titanate nanocube particles by solvothermal method and their characterization, J. Mater. Sci. 44(19) (2009) 5161-5166.

[21] J. Zhou, Z. Yang, Solvothermal growth of sub-10 nm monodispersed $\mathrm{BaTiO}_{3}$ nanocubes, Cryst. Eng. Comm. 15(44) (2013) 8912-8914.

[22] M. L. Moreira, G. P.Mambrini, D. P.Volanti, E. R.Leite, M. O. Orlandi, P. S.Pizani, V. R. Mastelaro, C. O. Paiva-Santos, E. Longo, J. A. Varela, Hydrothermal microwave: a new route to obtain photoluminescent crystalline $\mathrm{BaTiO}_{3}$ nanoparticles, Chem. Mater. 20(16) (2008) 5381-5387.

[23] M. E. Marssi, F. L. Marrec, I. A. Lukyanchuk, M. G. Karkut, Ferroelectric transition in an epitaxial barium titanate thin film: Raman spectroscopy and x-ray diffraction study, J. Appl. Phys. 94(5) (2003) $3307-3312$.

[24] O. E. J. James, C. H. Catherine, L. G. Bonnie, M. L. Malgorzata, E. R. Richard, Kinetics and mechanisms of hydrothermal synthesis of barium titanate, J. Am. Ceram. Soc. 79(11) (1996) 2929-2939.

[25] T. Yan, X. Liu, N. Wang, J. Chen, Synthesis of monodispersed barium titanate nanocrytals hydrothermal recrystallization of $\mathrm{BaTiO}_{3}$ nanospheres, J. Cryst. Growth. 281(2-4) (2005) 669-77.

[26] Y. H. Kim, Y. S. Kang, W. J. Lee, B. G. Jo, J. H. Jeong, Synthesis of Cu nanoparticles prepared by using thermal decomposition of Cu-oleate complex, Mol. Cryst. Liq. Cryst. 445(1) (2006) 231-238.

[27] Y.-J. Zhu, F. Chen, Microwave-assisted preparation of inorganic nanostructures in liquid phase, Chem. Rev., 114 (12) (2014) 6462-6555.

[27 28] J. Joo, S. G. Kwon, T. Yu, M. Cho, J. Lee, J. Yoon, T. Hyeon, Large scale synthesis of $\mathrm{TiO}_{2}$ nanorods via nonhydrolytic sol-gel ester elimination reaction and their application to photocatalytic inactivation of E. coli, J. Phys. Chem. B. 109(32) (2005) 15297-15302.

[28 29] C. R. Bullen, P. Mulvaney, Nucleation and growth kinetics of CdSe nanocrystals in octadecene, 
Nano Lett. 4 (12) (2004) 2303-2307.

[29 30] X. Wang, B. I. Lee, M. Hu, E. A. Payzant, D. A. Blom, Nanocrystalline $\mathrm{BaTiO}_{3}$ powder via a sol process ambient conditions, J. Eur. Ceram. Soc. 26(12) (2006) 2319-2326.

[30 31] S. Yoon, S. Baik, M. G. Kim, N. Shin, Formation Mechanisms of Tetragonal Barium Titanate Nanoparticles in Alkoxide-Hydroxide Sol-Precipitation Synthesis, J. Am. Ceram. Soc. 89(6) (2006) $1816-1821$

[3132] X. Zhu, Z. Zhang, J. Zhu, S. Zhou, Z. Liu, Morphology and atomic-scale surface structure of barium titanate nanocrystals formed at hydrothermal conditions, J. Cryst. Growth. 311(8) (2009) 2437-2442.

[32 33] J. Gao, H. Shi, H. Dong, R. Zhang, D. Chen, Factors influencing formation of highly dispersed $\mathrm{BaTiO}_{3}$ nanospheres with uniform sizes in static hydrothermal synthesis, J. Nanopart. Res. 17(7) (2015) 286 1-17.

[3334] Y. Ni, H. Zheng, N. Xiang., K. Yuan, J. Hong, Simple hydrothermal synthesis and photocatalytic performance of coral-like $\mathrm{BaTiO}_{3}$ nanostructures, RSC Adv. 5 (10) (2015) 7245-7252.

[3435] P. K. Dutta, R. Asiaie, S. A. Akbar, W. Zhu, Hydrothermal synthesis and dielectric properties of tetragonal $\mathrm{BaTiO}_{3}$, Chem. Mater. 6(9) (1994) 1542-1548.

[3536] Y. Cao, K. Zhu, Q. Wu, Q. Gu, J. Qiu, Hydrothermally synthesized barium titanate nanostructures from $\mathrm{K}_{2} \mathrm{Ti}_{4} \mathrm{O}_{9}$ precursors: Morphology evolution and its growth mechanism, Mater. Res. Bull. 57 (2014) 162-169.

[3637] D. R. Modeshia, R. I. Walton, Solvothermal synthesis of perovskites and pyrochlores: crystallization of functional oxides under mild conditions. Chem. Soc. Rev. 39(11) (2010) 4303-4325.

[3738] X. Wei, G. Xu, Z. Ren, Y. Wang, G. Shen, G. Han, Composition and shape control of single-crystalline $\mathrm{Ba}_{1-\mathrm{x}} \mathrm{Sr}_{\mathrm{x}} \mathrm{TiO}_{3}(\mathrm{x}=0-1)$ nanocrystals via a solvothermal route. J. Cryst. Growth. 310(18) (2008) 4132-4137.

[38] K. Suzuki, K. Kijimai, Optical band gap of barium titanate nanoparticles prepared by RF-plasma chemical vapor deposition, Japanese. J. Appl. Phys. 44(1) (2005) 2081-2082.

[3940] U. Gaya, A. Abdullah, Z. Zainal, M. Hussein, Photocatalytic degradation of 2,4-dichlorophenol in irradiated aqueous ZnO suspension, Int. J. Chem. 2(1) (2010) 180-193.

[4041] R. Su, Y. Shen, L. Li, D. Zhang, G. Yang, C. Gao, Y. Yang, Silver-modified nanosized ferroelectrics as a novel photocatalyst, Small. 11(2) (2015) 202-207.

[4142] H. Li, Y. Sang, S. Chang, X. Huang, Y. Zhang, R. Yang, H. Jiang, H. Liu, .Z. Wang, Enhanced 
ferroelectric-nanocrystal-based hybrid photocatalysis by ultrasonic-wave-generated piezophototronic effect, Nano Lett. 15(4) (2015) 2372-2379.

[42] Y. Cui, S. M. Goldup, S. Dunn, Photodegradation of Rhodamine B over Ag modified ferroelectric $\mathrm{BaTiO}_{3}$ under simulated solar light: pathways and mechanism, RSC Adv. 5(38) (2015) 30372-30379.

[43] A. T. Bell, The impact of nanoscience on heterogeneous catalysis, Science. 299(5613) (2003) 16881691.

[44] S. Li, L. Jing, W. Fu, L. Yang, B. Xin, H. Fu, Photoinduced charge property of nanosized perovskite-type $\mathrm{LaFeO}_{3}$ and its relationships with photocatalytic activity under visible irradiation, Mater. Res. Bull. 42(2) (2007) 203-212.

[45] Y. Cui, J. Briscoe, S. Dunn, Effect of ferroelectricity on solar-light-driven photocatalytic activity of $\mathrm{BaTiO}_{3}$ : influence on the carrier separation and stern layer formation, Chem. Mater. 25(21) (2013) $4215-4223$.

[46] J. L. Giocondi, G. S. Rohrer, The influence of the dipolar field effect on the photochemical reactivity of $\mathrm{Sr}_{2} \mathrm{Nb}_{2} \mathrm{O}_{7}$ and $\mathrm{BaTiO}_{3}$ microcrystals, Top. Catal. 49(1) (2008) 18-23.

\section{Table captions}

Table 1 Synthesis parameters for monodispersed $\mathrm{BaTiO}_{3}$ nanocuboids

Table 2 Comparing the photocatalytic activity of $\mathrm{BaTiO}_{3}$ nanocuboids with literatures

\section{Figure captions}

Fig. 1 XRD pattern (a), Raman spectrum (b), TEM image (c), SADE pattern (d), particle size distribution histograms pattern (e) obtained by counting 100 nanoparticles, the fast Fourier transform (FFT) profile (g) of the high-resolution TEM image (f) and scheme of the shape (h) of $\mathrm{BaTiO}_{3}$ nanocrystals prepared by microwave hydrothermal method using the precursor with molar composition of $\mathrm{Ba}(\mathrm{OH})_{2}: 0.83 \mathrm{TBOT}: 0.38 \mathrm{OA}: 394 \mathrm{H}_{2} \mathrm{O}$ at $200^{\circ} \mathrm{C}$ for $4 \mathrm{~h} . \quad \nabla$ indicates trace amounts of barium carbonate phase.

Fig. 2 (a) FT-IR spectra, static contact angle images of water droplets on the thin film compressed with $\mathrm{BaTiO}_{3}$ nanocrystals prepared with (b) and without (c) OA, and TG-DTG curves (d) of $\mathrm{BaTiO}_{3}$ nanocrystals prepared with OA. 
Fig. 3 TEM images of the products from four repeated experiments.

Fig. 34 (a) XRD patterns of $\mathrm{BaTiO}_{3}$ nanocrystals prepared with different molar ratio of $\mathrm{H}_{2} \mathrm{O} / \mathrm{Ba}$; TEM images of $\mathrm{BaTiO}_{3}$ nanocrystals prepared with $\mathrm{H}_{2} \mathrm{O} / \mathrm{Ba}$ molar ratio of (b) 99, (c) 197, (d) 394 and (e) 495. $\boldsymbol{\nabla}$ indicates trace amounts of barium carbonate phase.

Fig. 45 (a) XRD patterns of $\mathrm{BaTiO}_{3}$ nanocrystals prepared with different molar ratio of OA/Ba; TEM images of $\mathrm{BaTiO}_{3}$ nanocrystals prepared with OA/Ba molar ratio of (b) 0 , (c) 0.30 , (d) 0.56 and (e) 0.83 .

Fig. 56 TEM images of $\mathrm{BaTiO}_{3}$ nanocrystals prepared with molar ratio of $\mathrm{Ba}(\mathrm{OH})_{2}:$ Ti of (a) $1.0: 0.83$, (b) 1.66 : 0.83, (c) $\mathrm{Ba}(\mathrm{OH})_{2}: \mathrm{Ba}\left(\mathrm{NO}_{3}\right)_{2}: \mathrm{Ti}=1.0: 0.66: 0.83$, and (d) $\mathrm{Ba}(\mathrm{OH})_{2}: \mathrm{BaCl}_{2}: \mathrm{Ti}=1.0: 0.66: 0.83$.

Fig. 67 (a) XRD patterns of $\mathrm{BaTiO}_{3}$ nanocrystals prepared with different temperature and time; TEM images of $\mathrm{BaTiO}_{3}$ nanocrystals prepared at (b) $140^{\circ} \mathrm{C} / 4 \mathrm{~h}$, (c) $160^{\circ} \mathrm{C} / 4 \mathrm{~h}$, (d) $180^{\circ} \mathrm{C} / 4 \mathrm{~h}$, (e) $200^{\circ} \mathrm{C} / 4 \mathrm{~h}$, (f) $200^{\circ} \mathrm{C} / 2 \mathrm{~h},(\mathrm{~g}$ ) $200^{\circ} \mathrm{C} / 3 \mathrm{~h}$, (h) $200^{\circ} \mathrm{C} / 5 \mathrm{~h}$, and (i) $200^{\circ} \mathrm{C} / 6 \mathrm{~h}$.

Fig. 78 XRD patterns (a) and HRTEM images of the solid separated from the mother liquor which is microwave hydrothermally treated for (b-c) $5 \mathrm{~min}$, (d-e) $10 \mathrm{~min}$, (f-g) $15 \mathrm{~min}$ and (h-i) $30 \mathrm{~min}$.

Fig. 89 (a) UV-vis diffuse reflectance spectrum of $\mathrm{BaTiO}_{3}$ nanocuboids (the inset represents the indirect band gap); Photo catalytic degradation $\mathrm{C} / \mathrm{Co}$ values of $\mathrm{RhB} \mathrm{C} / \mathrm{C}_{\theta}-$ values respect to vs. time under UV irradition: (b) effect of the quantity of $\mathrm{BaTiO}_{3}$ nanocrystals. Condition:10, 20, 40 and $60 \mathrm{mg}$ of $\mathrm{BaTiO}_{3}$ are added into $30 \mathrm{~mL}$ of $10 \mathrm{mg} / \mathrm{L} \mathrm{RhB}$ solution, respectively. with ininitial concentration-of. (c) effect of the initial concentration of RhB solution.Condition: $30 \mathrm{~mL}$ RhB solution with $10 \mathrm{mg}$ of $\mathrm{BaTiO}_{3}$ nanocrystals as catalyst are added into 30 $\mathrm{mL}$ of 5, 10, 15 and $20 \mathrm{mg} / \mathrm{L} \mathrm{RhB}$ solution, respectively. Inset (b) presents the adsorption of $\mathrm{RhB}$ on $\mathrm{BaTiO}_{3}$ nanocrystals in dark, and inset (c) is absorption spectra of $\mathrm{RhB}(5 \mathrm{mg} / \mathrm{L})$ aqueous solution in presence of $\mathrm{BaTiO}_{3}$ nanocrystals during UV irradiation.

Fig. 10 TEM images of $\mathrm{BaTiO}_{3}$ after (a) calcined in muffle oven at $500{ }^{\circ} \mathrm{C}$ for $2 \mathrm{~h}$ and (b) washed several times with ethanol, (c) IR spectra and (d) $\mathrm{C} / \mathrm{Co}$ values of $\mathrm{RhB}$ vs. time under $\mathrm{UV}$ irradition for $\mathrm{BaTiO}_{3}$ before and after washed several times with ethanol. Photocatalysis is carried out with $10 \mathrm{mg}$ of $\mathrm{BaTiO}_{3}$ in $30 \mathrm{~mL}$ of $5 \mathrm{mg} / \mathrm{L} \mathrm{RhB}$ solution. 
Table 1

\begin{tabular}{|c|c|c|c|c|c|c|c|c|}
\hline \multirow[t]{2}{*}{ No. } & \multicolumn{4}{|c|}{ Molar } & \multicolumn{2}{|c|}{ atio } & \multirow{2}{*}{$\begin{array}{c}\mathrm{T} \\
\left({ }^{\circ} \mathrm{C}\right)\end{array}$} & \multirow{2}{*}{$\begin{array}{c}\mathrm{t} \\
\text { (h) }\end{array}$} \\
\hline & $\mathrm{X}$ & $\mathrm{y}$ & $\mathrm{Z}$ & $\mathrm{f}$ & $\bar{j}$ & $\mathrm{k}$ & & \\
\hline S1 & 1 & 0 & 0 & 0.83 & 0.30 & 99 & 200 & 4 \\
\hline $\mathrm{S} 2$ & 1 & 0 & 0 & 0.83 & 0.30 & 197 & 200 & 4 \\
\hline S3 & 1 & 0 & 0 & 0.83 & 0.30 & 394 & 200 & 4 \\
\hline S4 & 1 & 0 & 0 & 0.83 & 0.30 & 495 & 200 & 4 \\
\hline S5 & 1 & 0 & 0 & 0.83 & 0 & 394 & 200 & 4 \\
\hline S6 & 1 & 0 & 0 & 0.83 & 0.56 & 394 & 200 & 4 \\
\hline S7 & 1 & 0 & 0 & 0.83 & 0.83 & 394 & 200 & 4 \\
\hline S8 & 1 & 0 & 0 & 0.83 & 1.09 & 394 & 200 & 4 \\
\hline S9 & 1.66 & 0 & 0 & 0.83 & 0.30 & 394 & 200 & 4 \\
\hline $\mathrm{S} 10$ & 1 & 0.66 & 0 & 0.83 & 0.30 & 394 & 200 & 4 \\
\hline $\mathrm{S} 11$ & 1 & 0 & 0.66 & 0.83 & 0.30 & 394 & 200 & 4 \\
\hline $\mathrm{S} 12$ & 1 & 0 & 0 & 0.83 & 0.30 & 394 & 140 & 4 \\
\hline $\mathrm{S} 13$ & 1 & 0 & 0 & 0.83 & 0.30 & 394 & 160 & 4 \\
\hline S14 & 1 & 0 & 0 & 0.83 & 0.30 & 394 & 180 & 4 \\
\hline $\mathrm{S} 15$ & 1 & 0 & 0 & 0.83 & 0.30 & 394 & 200 & 2 \\
\hline S16 & 1 & 0 & 0 & 0.83 & 0.30 & 394 & 200 & 3 \\
\hline S17 & 1 & 0 & 0 & 0.83 & 0.30 & 394 & 200 & 5 \\
\hline $\mathrm{S} 18$ & 1 & 0 & 0 & 0.83 & 0.30 & 394 & 200 & 6 \\
\hline
\end{tabular}

${ }^{\mathrm{a}}$ Molar composition of the precursor : $\mathrm{B} \mathrm{Ba}(\mathrm{OH})_{2}: \mathrm{y} \mathrm{Ba}\left(\mathrm{NO}_{3}\right)_{2}: \mathrm{z} \mathrm{BaCl}_{2}$ : f Ti(OBu $)_{4}$ : j OA : k H $\mathrm{H}_{2} \mathrm{O}$. 
Table 2

\begin{tabular}{|c|c|c|c|c|c|c|c|c|c|}
\hline \multicolumn{2}{|c|}{ Rh B solution } & \multirow{2}{*}{$\begin{array}{l}\text { Irraditio } \\
\mathrm{n} \text { light }\end{array}$} & \multicolumn{4}{|c|}{$\mathrm{BaTiO}_{3}$} & \multirow{2}{*}{$\begin{array}{c}\text { Irradiation } \\
\text { time } \\
(\mathrm{min})\end{array}$} & \multirow{2}{*}{$\begin{array}{c}\text { Degradatio } \\
\mathrm{n} \text { efficiency } \\
(\%)\end{array}$} & \multirow[t]{2}{*}{ Ref. } \\
\hline $\begin{array}{c}\text { Volume } \\
/ \mathrm{mL}\end{array}$ & $\begin{array}{c}\text { Concentration } \\
/ \mathrm{mg} / \mathrm{L}\end{array}$ & & $\begin{array}{l}\text { Average } \\
\text { size }(\mathrm{nm})\end{array}$ & Shape & $\begin{array}{l}\text { Crystal } \\
\text { structure }\end{array}$ & $\begin{array}{c}\text { Amount } \\
(\mathrm{mg})\end{array}$ & & & \\
\hline 100 & 10 & UV & 7.5 & cube & tetragonal & 100 & 40 & 38 & [4041] \\
\hline 20 & 15 & UV & 87 & cube & tetragonal & 20 & 180 & $\approx 5$ & [4142] \\
\hline \multirow[t]{3}{*}{50} & 10 & Simulat & 622 & irregular & cubic & 150 & 60 & $\approx 20$ & [45] \\
\hline & & ed & & & /tetragona & & & & \\
\hline & & sunlight & & & 1 & & & & \\
\hline 25 & 10 & UV & 300 & subsphaeroi & tetragonal & 25 & 60 & $\approx 10$ & [4] \\
\hline \multirow[t]{3}{*}{30} & 10 & UV & 13 & cube & cubic & 10 & 40 & 64 & This \\
\hline & & & & & /tetragona & & 60 & 87 & work \\
\hline & & & & & 1 & & 220 & $\approx 100$ & \\
\hline
\end{tabular}


FIGURES
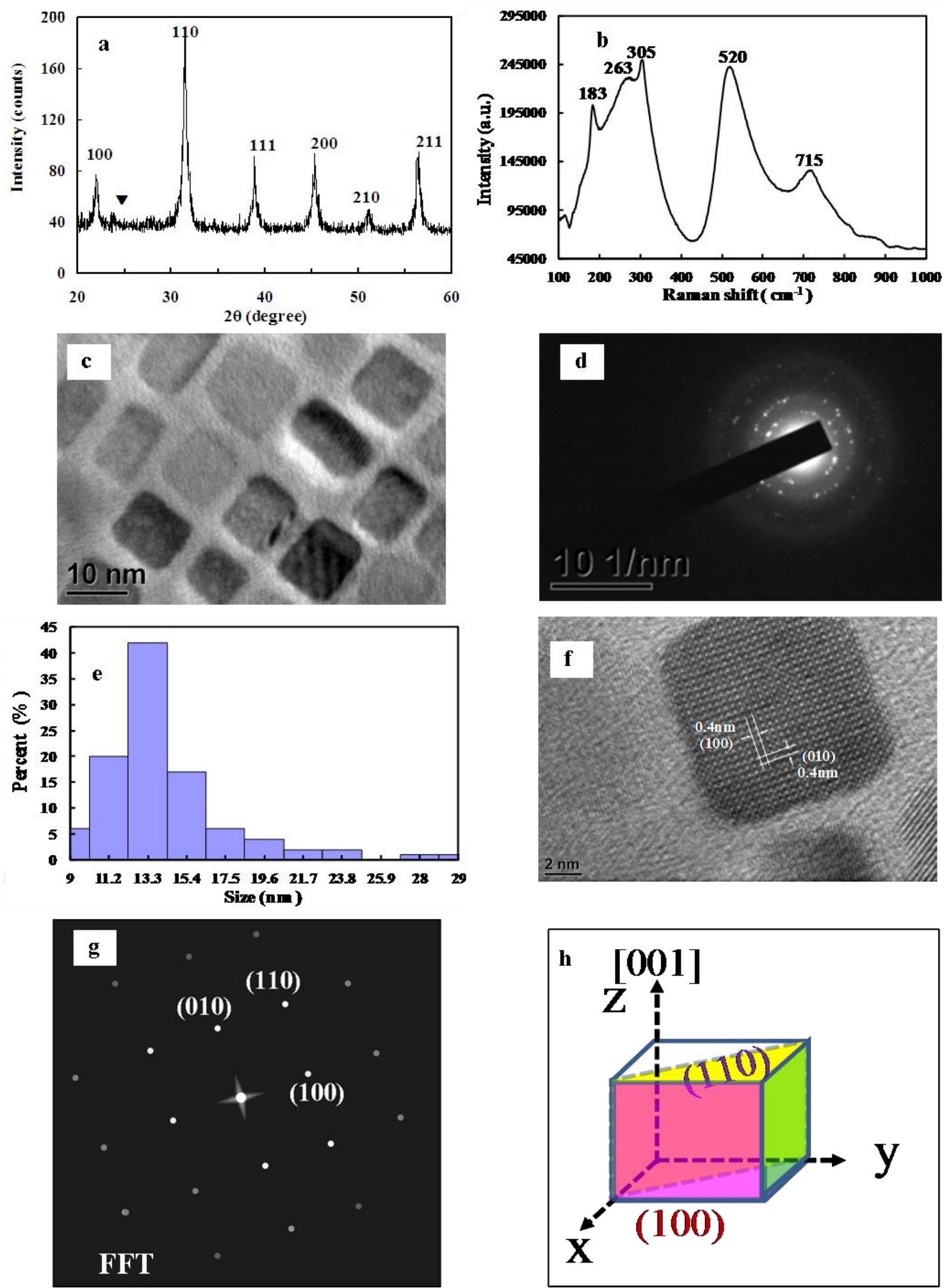

Fig. 1 

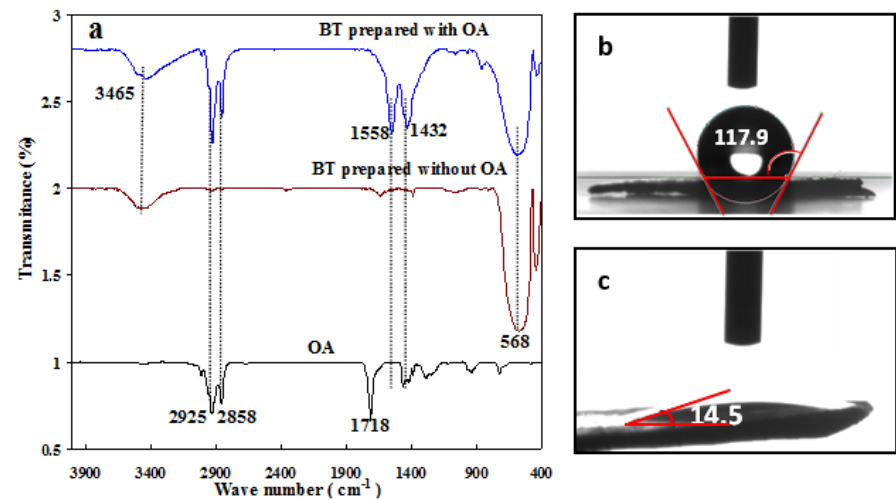

Fig. 2

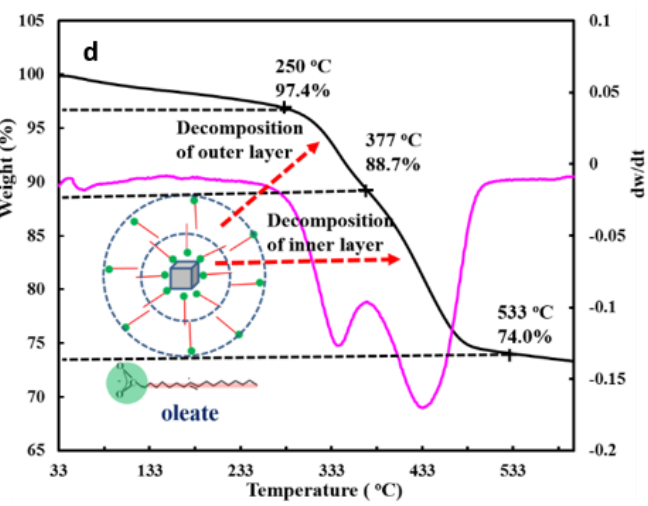



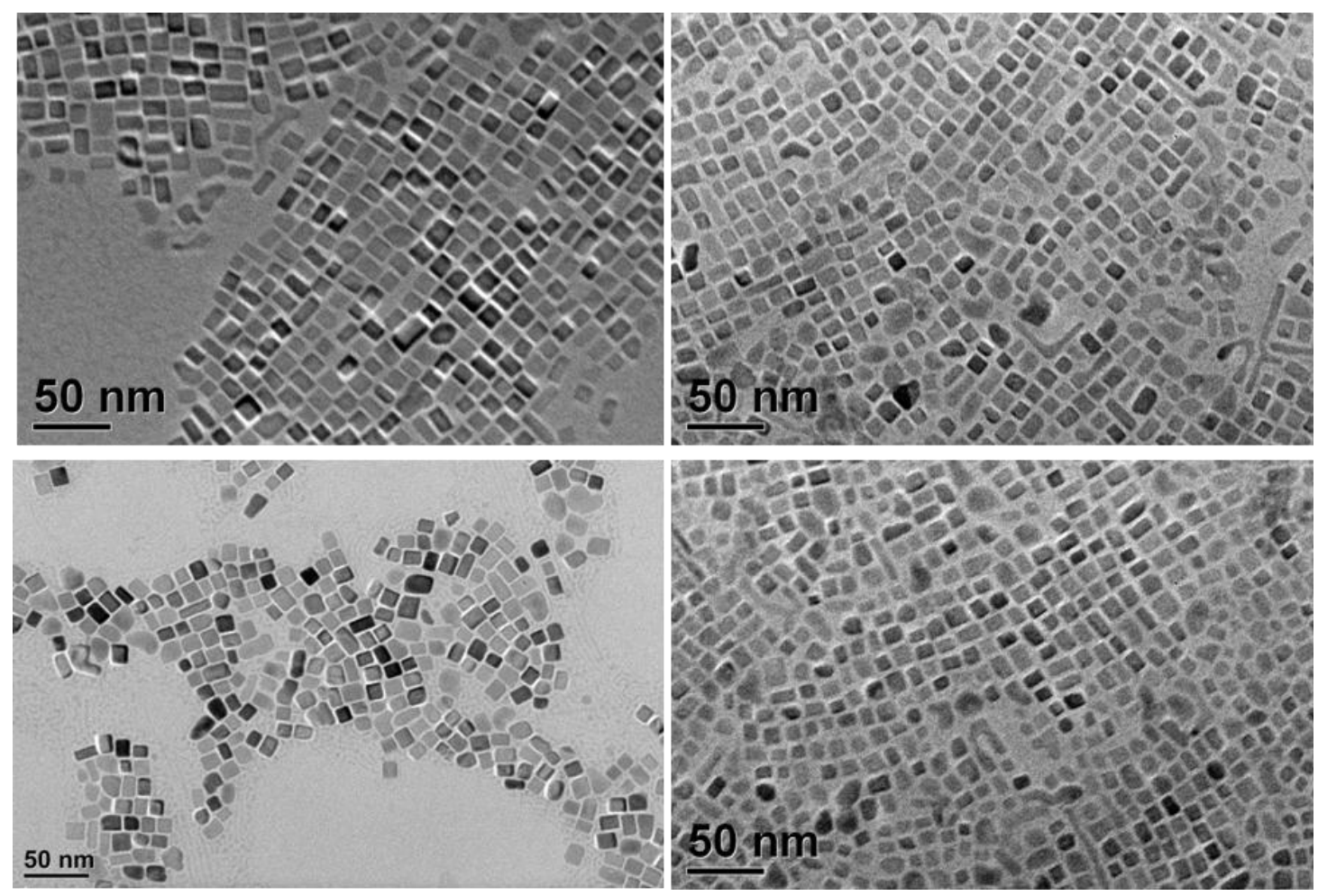

Fig. 3 

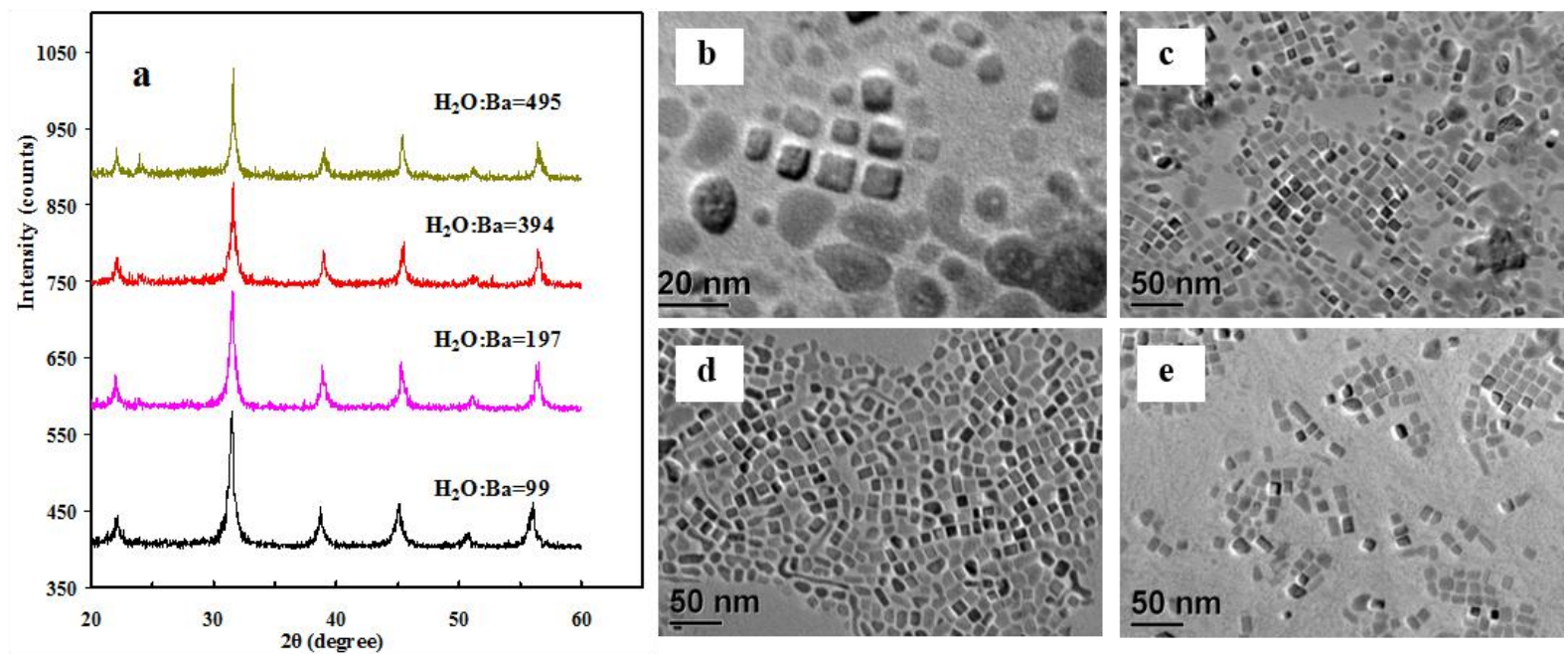

Fig. 34 


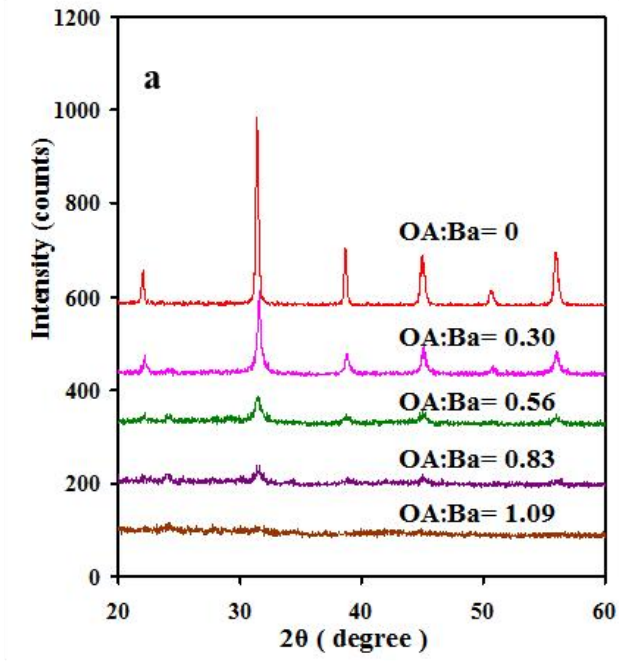

60
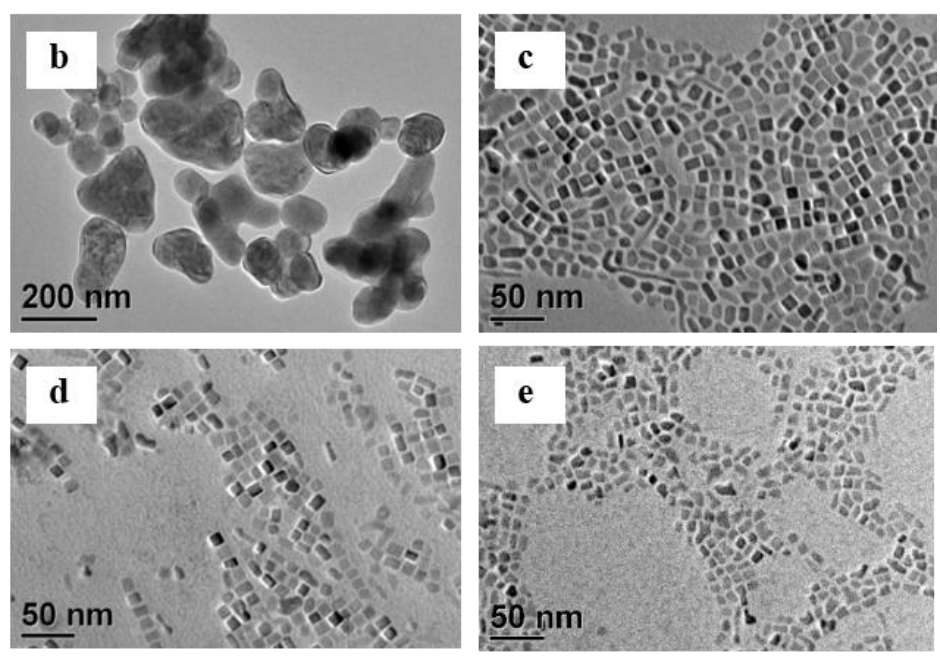

Fig. 45 

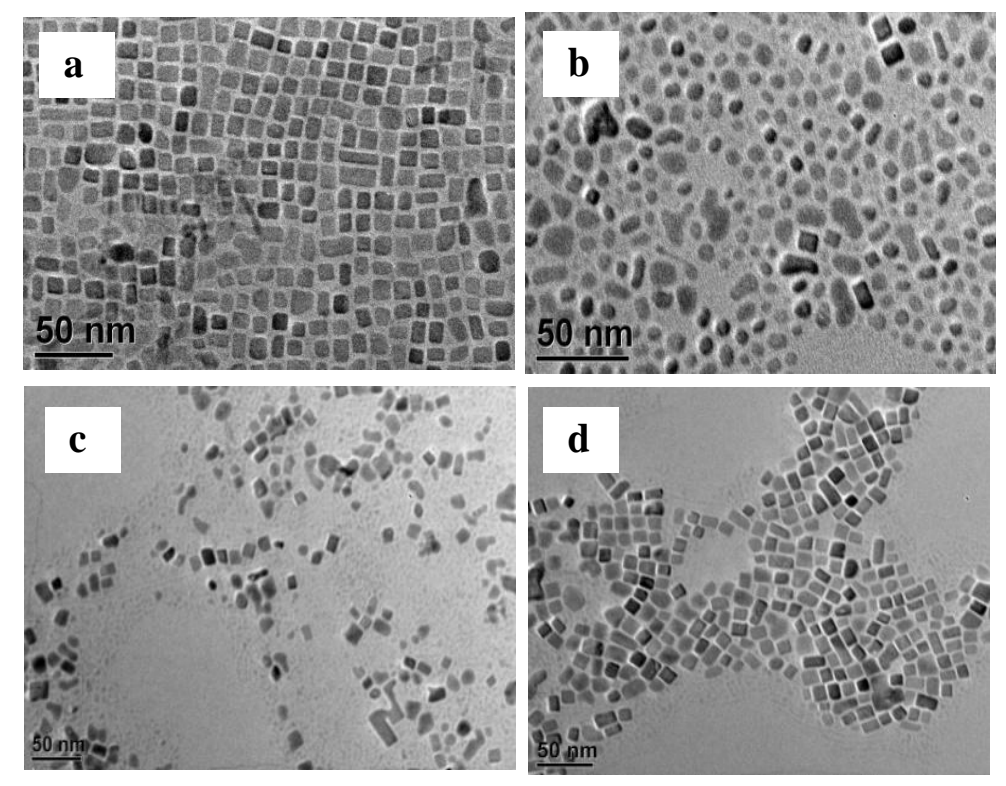

Fig. 56 

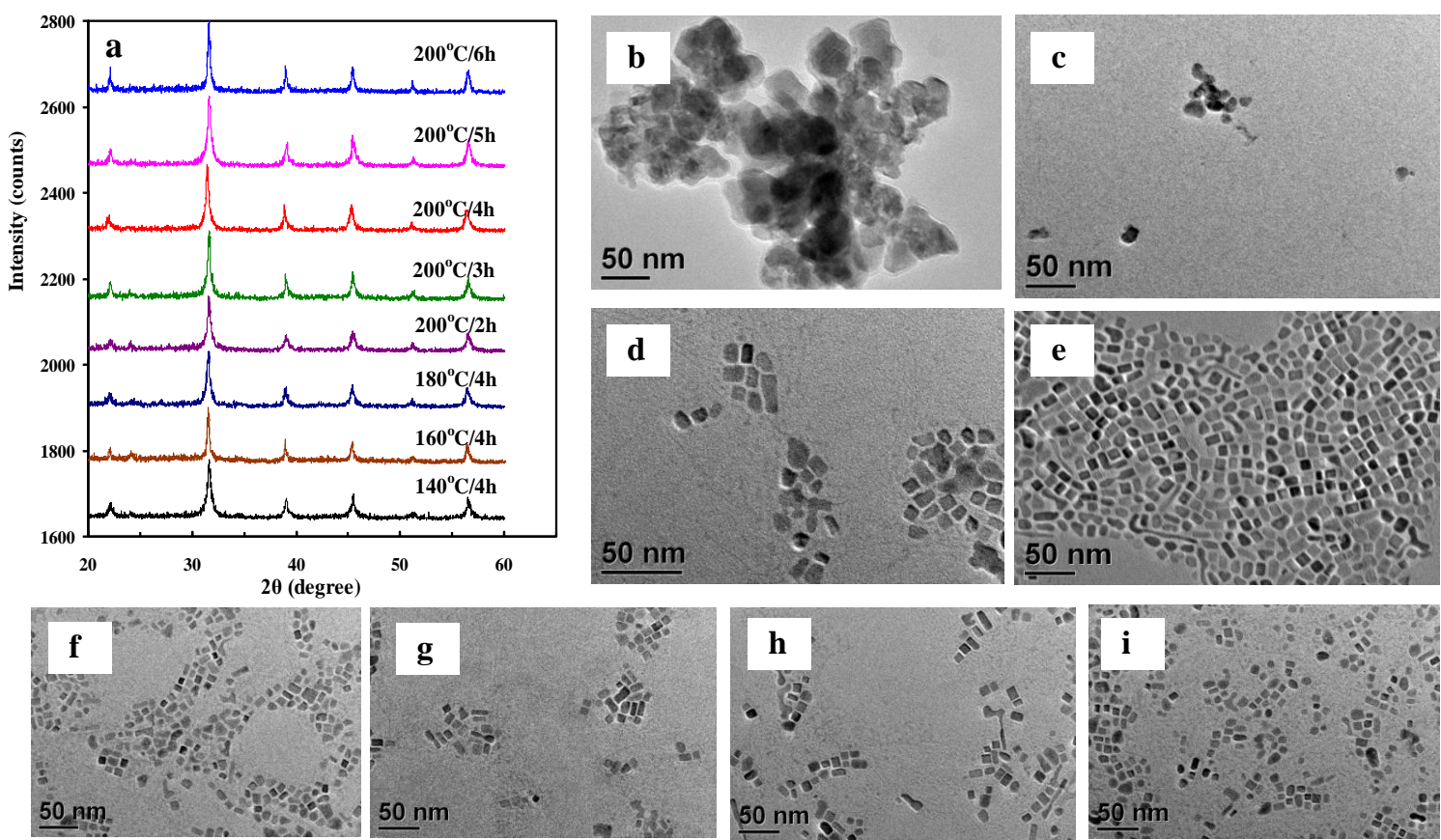

Fig. 67 

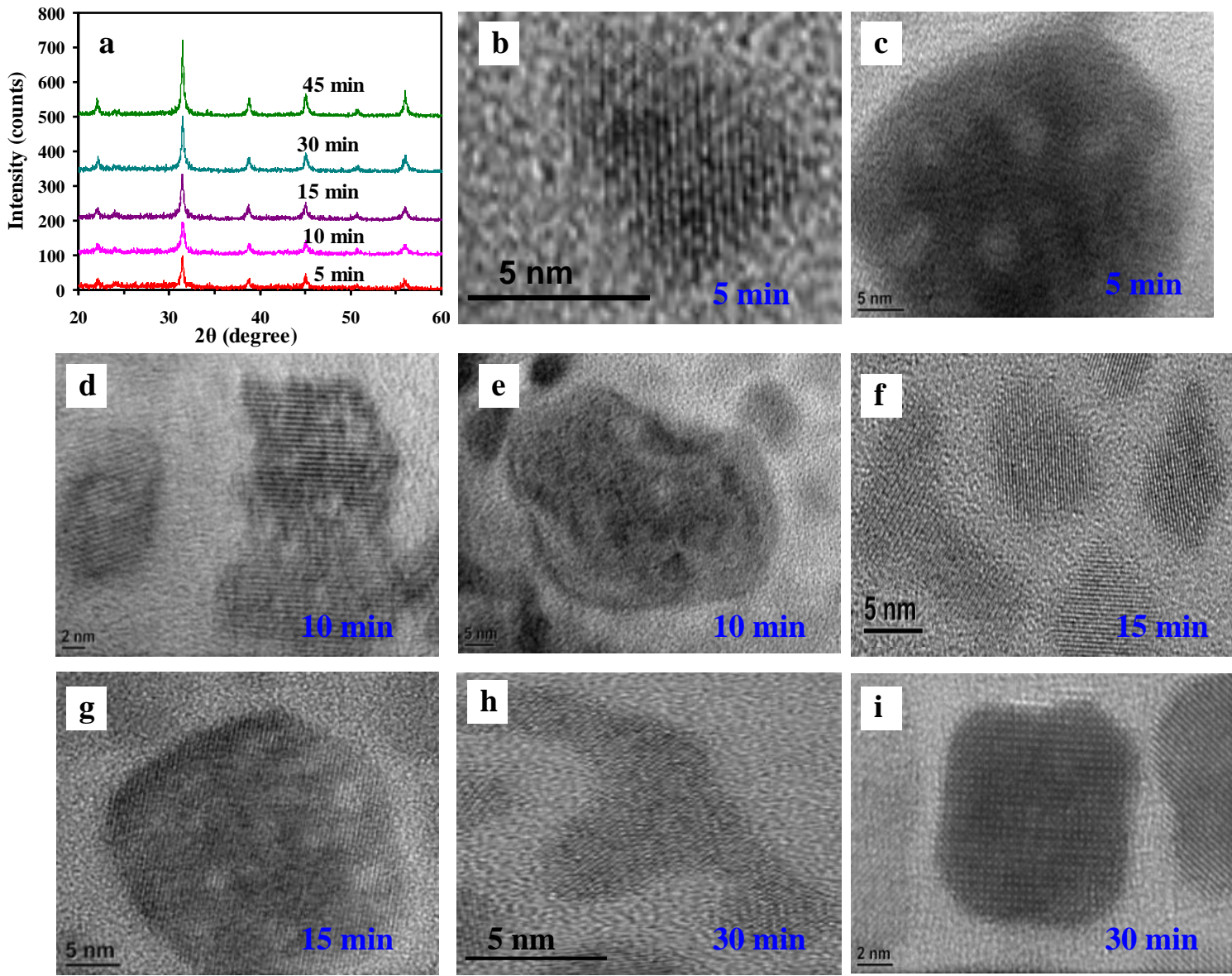

Fig. 78 

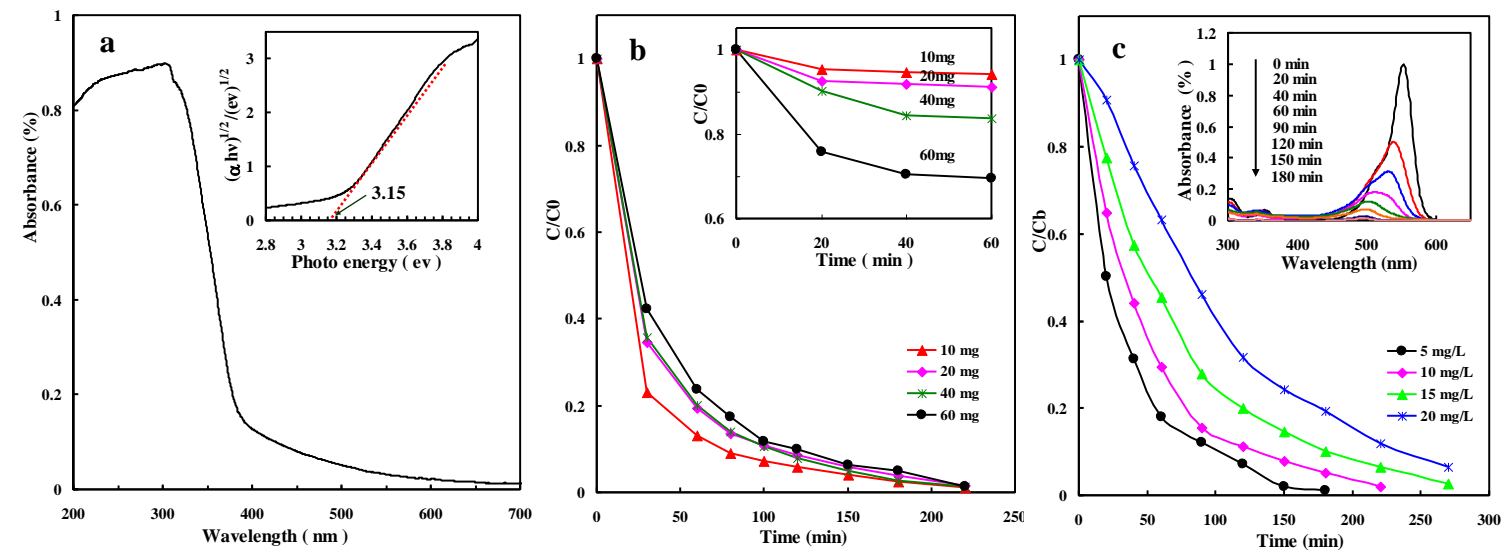

Fig. 89 

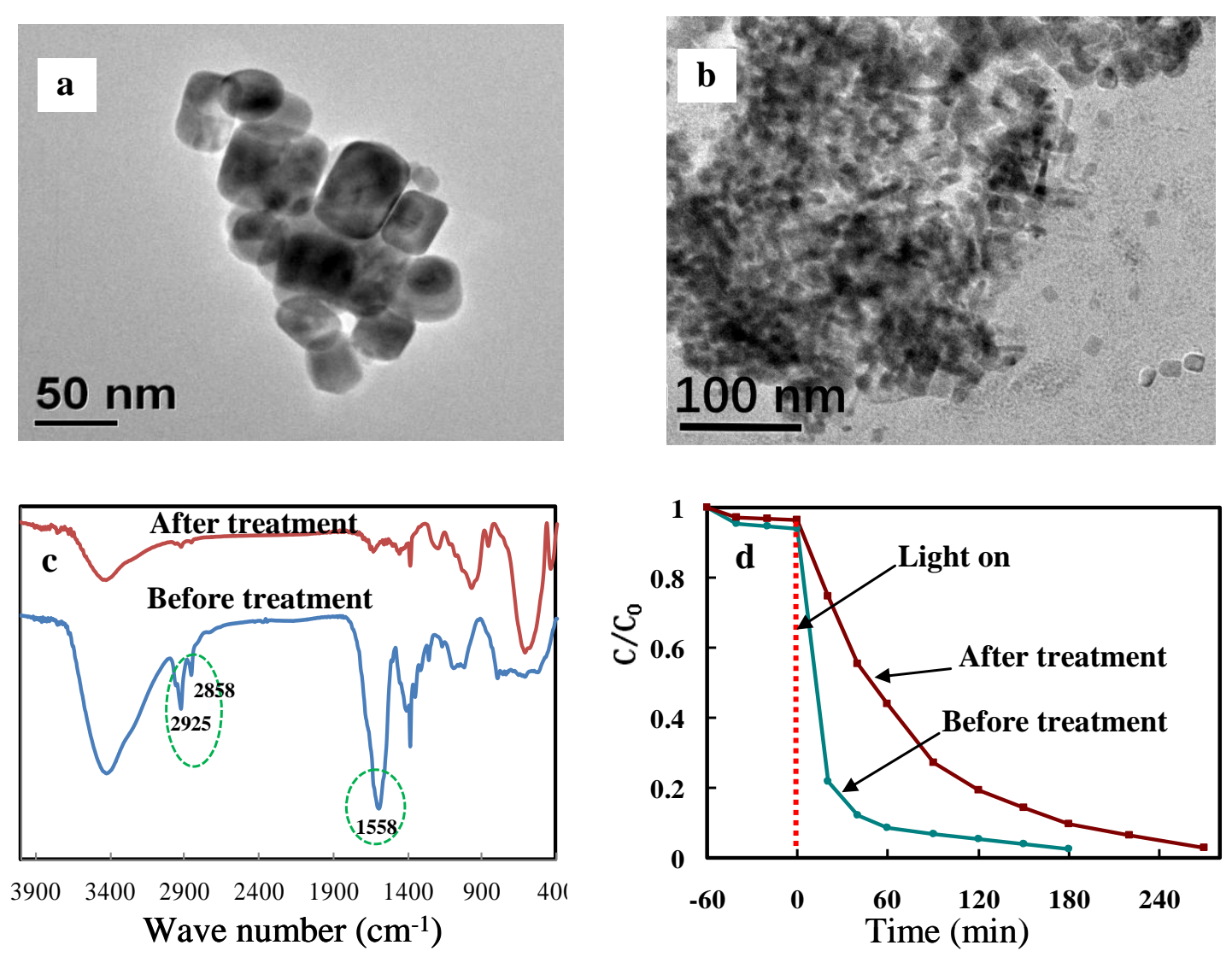

Fig. 10 

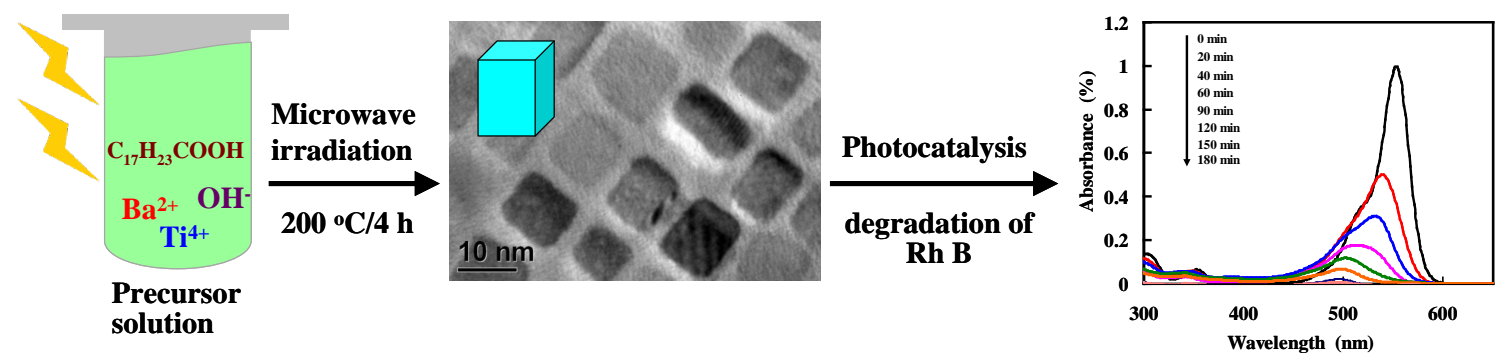